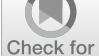

Check for

updates

Cite as

Nano-Micro Lett.

(2019) 11:16

Received: 11 December 2018

Accepted: 21 January 2019

Published online: 27 February 2019

(C) The Author(s) 2019

\section{Lead-Free Halide Double Perovskite Materials: A New Superstar Toward Green and Stable Optoelectronic Applications}

\author{
Liang Chu ${ }^{1,2}$, Waqar Ahmad ${ }^{3}$, Wei Liu², Jian Yang ${ }^{2}$, Rui Zhang ${ }^{2}$, Yan Sun ${ }^{1}$, \\ Jianping Yang ${ }^{1}$, Xing'ao $\mathrm{Li}^{1,2} \bowtie$ \\ $\triangle$ Jianping Yang, yangjp@njupt.edu.cn; Xing'ao Li, iamxali@njupt.edu.cn \\ 1 New Energy Technology Engineering Laboratory of Jiangsu Province \& School of Science, Nanjing \\ University of Posts and Telecommunications (NJUPT), Nanjing 210023, People's Republic of China \\ 2 Key Laboratory for Organic Electronics \& Information Displays \& Institute of Advanced Materials, \\ Jiangsu National Synergistic Innovation Center for Advanced Materials, School of Materials Science \\ and Engineering, Nanjing University of Posts and Telecommunications (NJUPT), Nanjing 210023, \\ People's Republic of China \\ 3 Wuhan National Laboratory for Optoelectronics (WNLO), Huazhong University of Science and Technology \\ (HUST), Wuhan 430074, People's Republic of China
}

\title{
HIGHLIGHTS
}

- Lead-based halide perovskite materials have revealed excellent properties in optoelectronic applications. However, the material stability and the toxicity of lead still hinder their large-scale commercial applications.

- Lead-free halide double perovskite materials possess the characteristics of environmental friendliness, exceptional stability and tunable optoelectronic properties.

- A limited number of halide double perovskites have been synthesized, and extremely few have been developed for optoelectronic applications. Continuing effort is needed to explore more halide double perovskites and modulate the properties for their further applications.

ABSTRACT Lead-based halide perovskites have emerged as excellent semiconductors for a broad range of optoelectronic applications, such as photovoltaics, lighting, lasing and photon detection. However, toxicity of lead and poor stability still represent significant challenges. Fortunately, halide double perovskite materials with formula of $\mathrm{A}_{2} \mathrm{M}(\mathrm{I}) \mathrm{M}(\mathrm{III}) \mathrm{X}_{6}$ or $\mathrm{A}_{2} \mathrm{M}(\mathrm{IV}) \mathrm{X}_{6}$ could be potentially regarded as stable and green alternatives for optoelectronic applications, where two divalent lead ions are substituted by combining one monovalent and one trivalent ions, or one tetravalent ion. Here, the article provides an up-to-date review on the developments of halide double perovskite materials and their related optoelectronic applications including photodetectors, X-ray detectors, photocatalyst, light-emitting diodes and solar cells. The synthesized halide double perovskite materials exhibit exceptional stability, and a few possess superior optoelectronic properties. However, the number of synthesized halide double perovskites is limited, and more limited materials have been developed for optoelectronic applications to date. In addition, the band structures and carrier transport properties of the materials are still not desired, and

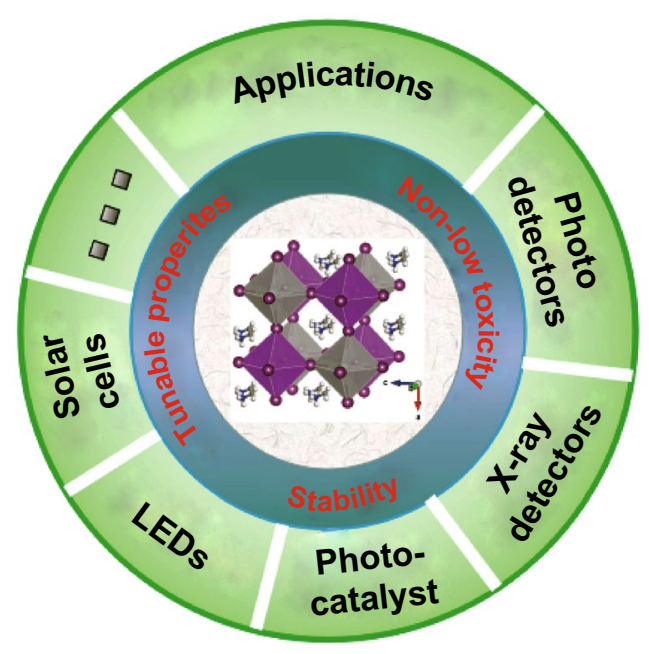


the films still manifest low quality for photovoltaic applications. Therefore, we propose that continuing efforts are needed to develop more halide double perovskites, modulate the properties and grow high-quality films, with the aim of opening the wild practical applications.

KEYWORDS Halide double perovskite; Optoelectronic applications; Efficiency; Stability; Toxicity

\section{Introduction}

Halide perovskites with the generic formula $\mathrm{AM}(\mathrm{II}) \mathrm{X}_{3}(\mathrm{~A}$ : $\mathrm{CH}_{3} \mathrm{NH}_{3}^{+}, \mathrm{CH}\left(\mathrm{NH}_{2}\right)_{2}^{+}, \mathrm{Cs}^{+} ; \mathrm{M}(\mathrm{II}): \mathrm{Pb}^{2+}, \mathrm{Sn}^{2+} ; \mathrm{X}: \mathrm{I}^{-}, \mathrm{Br}^{-}$, $\mathrm{Cl}^{-}$) can be divided into two broad categories according to the A-location cation: organic-inorganic hybrid and allinorganic halide perovskites. Initially, halide perovskites of $\mathrm{CH}_{3} \mathrm{NH}_{3} \mathrm{PbX}_{3}(\mathrm{X}=\mathrm{Br}$, I) were utilized as light sensitizer to replace dyes in dye-sensitized solar cells with liquid electrolyte in 2009 [1]. However, due to the underdeveloped efficiency $\sim 3.8 \%$ and stability, the initial perovskite solar cells (PSCs) did not capture widespread attention. Until 2012, a solid hole transport layer was substituted for the liquid electrolyte to develop all-solid-state PSCs. Most strikingly, the efficiency and stability were simultaneously distinctly improved [2], which stimulated "perovskite fever" [3-5]. Recently, the certified efficiency of PSCs has risen to $23.7 \%$, which is comparable to conventional silicon solar cells [6]. The rocketing improvement of efficiency is attributed to the suitable direct bandgap, strong absorption coefficient, longrange charge diffusion length, balanced electron-hole mobility, high dielectric constant, excellent carrier mobility and small exciton binding energy of halide perovskites [7-10]. Besides solar cells, these materials have been applied in other optoelectronic applications, such as light-emitting diodes (LEDs) [11, 12], lasers [13], photodetectors [14, 15] and X-ray detectors [16].

Although efficiency of PSCs has been progressively grown, there are still huge barriers which limit the commercial applications. For instance, the long-term stability over 10 years is the most critical obstacle to restrict the commercialization [17]. Currently, the PSCs cannot remain stable more than 1 year outdoors, whereas silicon solar cells are usually guaranteed to work for at least 25 years. Moisture, temperature, oxygen and extreme light levels all cause PSCs to decompose. Moisture is the worst problem because reaction with the water forms hydrates to destroy the crystal structures [18]. To improve the stability of PSCs, six main solutions have been adopted: (1) regulating the crystal structures to improve phase stability by doping [19], (2) reducing crystal defects to limit penetrating channels from external environment [20, 21], (3) designing new stable halide perovskite materials [22, 23], (4) using stable inorganic charge transport layers [24], (5) adopting 2D halide perovskite materials [25, 26] and (6) packaging the devices [27]. Based on the above solutions, cell lifetimes have extended from a few days to months. Nevertheless, there is still a long way to go toward long-time stability over tens of years. Also, toxic lead is still necessary to achieve high performance. Lead pollution will do serious harm to human health, such as fatigue, muscle weakness, clumsiness and clouded consciousness [28]. Extensive efforts have been paid to design new non- $/$ low-toxic and stable halide perovskites for solar cells as well as other optoelectronic applications [29-31]. $\mathrm{Sn}^{2+}$ and $\mathrm{Ge}^{2+}$ ions could be expected to replace $\mathrm{Pb}^{2+}$ ions in perovskites. However, the $\mathrm{Sn}^{2+}$ and $\mathrm{Ge}^{2+}$ cations tend to undergo oxidation due to the high-energy-lying $5 \mathrm{~s}$ orbitals, rendering the corresponding perovskite extremely unstable in ambient atmosphere [30, 31]. Similarly, $\mathrm{Bi}^{3+}$ and $\mathrm{Sb}^{3+}$ ions with the similar isoelectronic structure have been substituted for $\mathrm{Pb}^{2+}$ ions to develop stable and lead-free perovskites. However, inherently low-dimensional structures of the $\mathrm{A}_{3} \mathrm{M}(\mathrm{III})_{2} \mathrm{X}_{9}$ perovskites result in less impressive performance [22, 23]. Afterward, doping bivalent metal ions in moderation not only decreases lead content, but also enhances the efficiency and stability, such as $\mathrm{Sr}^{2+}$ [32], $\mathrm{Co}^{2+}$ [33] and $\mathrm{Zn}^{2+}$ [34]. The main reason is that the metal ion-based doping can moderately improve the quality of perovskite films. Simultaneously, doping a certain type of heterovalent metal ions can engineer the band structure of perovskite to enhance the performance, such as $\mathrm{Ag}^{+}$[35], $\mathrm{Sb}^{3+}$ [36] and $\mathrm{Bi}^{3+}$ [37]. However, the doping method cannot thoroughly solve any issues of stability or toxicity.

Recently, halide double perovskites $\left(\mathrm{A}_{2} \mathrm{M}(\mathrm{I}) \mathrm{M}(\mathrm{III}) \mathrm{X}_{6}\right.$, $\mathrm{A}_{2} \mathrm{M}(\mathrm{IV}) \mathrm{X}_{6}$ ) have been proposed as stable and green alternatives to lead halide perovskites, where two toxic lead ions are substituted by combining one monovalent and one trivalent ions, or one tetravalent ion and one vacancy site (marked as " $\square$ ") to yield the same overall charge balance as the conventional perovskites, as shown in Fig. 1a [38]. The formula of $\mathrm{A}_{2} \mathrm{M}(\mathrm{IV}) \mathrm{X}_{6}$ is considered as vacancy-ordered halide double perovskites, which is the analogy of $\mathrm{A}_{2} \mathrm{M}(\mathrm{I})$ 
(a)

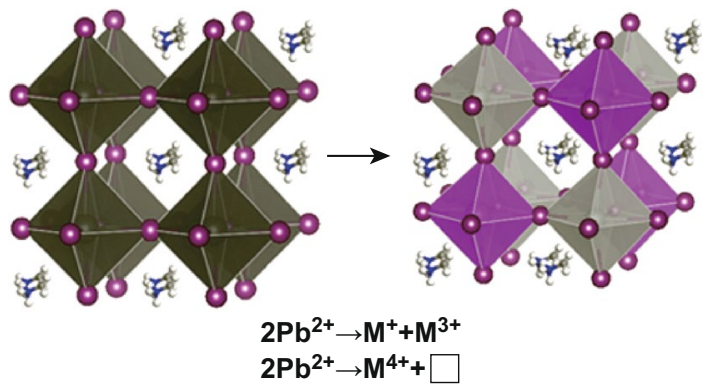

(b)

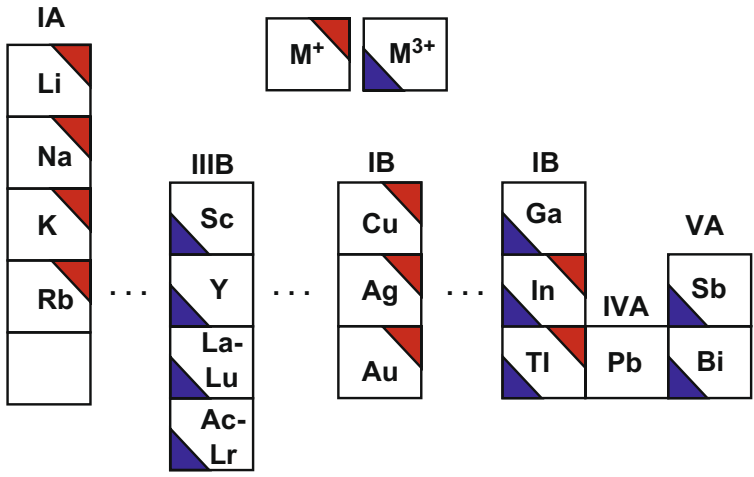

Fig. 1 a Schematic illustration of the transformation from $\mathrm{APbX}_{3}$ to $\mathrm{A}_{2} \mathrm{M}(\mathrm{I}) \mathrm{M}(\mathrm{III}) \mathrm{X}_{6}$ or $\mathrm{A}_{2} \mathrm{M}(\mathrm{IV}) \mathrm{X}_{6}$, where two toxic $\mathrm{Pb}^{2+}$ ions are substituted by combining $\mathrm{M}^{+}$and $\mathrm{M}^{3+}$ ions (or $\mathrm{M}^{4+}$ ion). " $\square$ " denotes $\mathrm{M}$-site vacancy. $\mathbf{b}$ Elements of $\mathrm{M}$-location cations with $\mathrm{M}^{+}$and $\mathrm{M}^{3+}$ in the periodic table for halide double perovskites. When any $\mathrm{M}$-site elements are localized at IA or IIIA groups of the periodic table, the materials have direct bandgaps

$\mathrm{M}(\mathrm{III}) \mathrm{X}_{6}$. Because of the cubic structure $(\overline{\mathrm{Fm} 3} \mathrm{~m})$ to extend three dimensions with corner-sharing metal halide octahedra, halide double perovskites have attracted extensive attention as promising optoelectronic candidates. In this review, we highlight lead-free halide double perovskite materials and their related optoelectronic applications including photodetectors, X-ray detectors, photocatalyst, LEDs and solar cells. The synthesized halide double perovskites exhibited pleasurable stability. But only a limited number of halide double perovskites have been synthesized, and extremely few have been developed for optoelectronic applications. In addition, the band structures and carrier transport properties of the materials are still not desired, and the films still manifest low quality for photovoltaic applications. It is universally acknowledged that significant effort is needed to discover more candidates and modulate the properties for their further applications.

\section{Halide Double Perovskite Materials}

Besides stability, the band structures and carrier transport properties of the materials predetermine to a large extent the specific applications and their performance. In halide perovskites with the chemical formula $\mathrm{APbX}_{3}$, the valence and conduction bands are predominantly made up of the $\mathrm{Pb}-6 \mathrm{p}$ and $\mathrm{X}-5 \mathrm{p}$ orbitals. In addition, the size of the A-location cation affects the $\mathrm{PbX}_{6}$ octahedra to distort/tilt, which can slightly modify the band structures [39]. Similarly, the band structures of the halide double perovskites are mainly decided by the M(I)-, M(III)- (or M(IV)-) and X-site atoms. The elements of M-location cations with monovalent and trivalent in the periodic table toward halide double perovskites are shown in Fig. 1b. The elements in IA, IB and IIIA groups can occupy the $\mathrm{M}^{+}$sites, and the elements in IIB, IIIA and VA groups are found at the $\mathrm{M}^{3+}$ sites. When any $\mathrm{M}$-site elements of the halide double perovskites are localized at IA or IIIA groups of the periodic table, the materials have direct bandgaps. The In and Tl elements in IIIA group possess valencies +1 and +3 . The vacancy-ordered halide double perovskites $\left(\mathrm{A}_{2} \mathrm{M}(\mathrm{IV}) \mathrm{X}_{6}\right)$ all have direct bandgaps. Theoretically, there are a lot of halide double perovskites, though the exact formula must be considered two aspects of the Goldschmidt's rule and thermodynamic stability [40]. However, only a limited number of halide double perovskites have been synthesized so far, as listed in Table 1 including their synthetic methods, where $\mathrm{MA}$ is $\mathrm{CH}_{3} \mathrm{NH}_{3}$.

\subsection{All-Inorganic Halide Double Perovskites}

Initially, all-inorganic halide double perovskite of $\mathrm{Cs}_{2} \mathrm{NaAmCl}_{6}$ was prepared in 1968 by evaporating $\mathrm{HCl}$ solution containing cations to dryness [41]. Afterward, a few all-inorganic halide double perovskites $\left(\mathrm{Cs}_{2} \mathrm{NaM}(\mathrm{III})\right.$ $\mathrm{Cl}_{6}$ ) were fabricated by the same method [42-44]. In those days, ferroelectric phase transition was considered particularly attracted for all-inorganic halide double perovskites [45-47], which was observed on the cooling $\mathrm{Cs}_{2} \mathrm{NaBiCl}_{6}$ [47].

In light of the obsessive interest in halide perovskites, halide double perovskites have attained great concern in recent 2 years. In 2016, three different groups almost simultaneously reported $\mathrm{Cs}_{2} \mathrm{AgBiX}_{6}(\mathrm{X}=\mathrm{Cl}$ or $\mathrm{Br})$ as a promising alternative to the lead halide perovskites, which crystallizes 
Table 1 Summary of the prepared halide double perovskites

\begin{tabular}{|c|c|c|c|}
\hline Materials & Morphology & Synthetic method & References \\
\hline $\begin{array}{l}\mathrm{Cs}_{2} \mathrm{NaMCl}_{6} \\
(\mathrm{M}=\mathrm{Am}, \mathrm{Bk}, \mathrm{Tl}, \mathrm{Bi}, \mathrm{Lu} \text {, etc. })\end{array}$ & Powder or single crystal & $\begin{array}{l}\text { Evaporating } \mathrm{HCl} \text { solution to dryness, or heating anhydrous chlorides, } \\
\text { or precipitating from cold } \mathrm{HCl} \text { solution, or growing crystals from } \\
\text { dilute } \mathrm{HCl} \text { solution by cooling evaporation }\end{array}$ & {$[41-47]$} \\
\hline \multirow[t]{2}{*}{$\mathrm{Cs}_{2} \mathrm{AgBiCl}_{6}$} & Powder & $\begin{array}{l}\text { Melt crystallization } \\
\text { Precipitation from heated acid solution }\end{array}$ & {$[48,49]$} \\
\hline & Nanocrystal & $\begin{array}{l}\text { Hot injection } \\
\text { Antisolvent recrystallization }\end{array}$ & {$[50,51]$} \\
\hline \multirow[t]{3}{*}{$\mathrm{Cs}_{2} \mathrm{AgBiBr}_{6}$} & Powder & $\begin{array}{l}\text { Melt crystallization } \\
\text { Precipitation from heated acid solution }\end{array}$ & {$[48]$} \\
\hline & Single crystal & Cooling crystallization & {$[52,54,55]$} \\
\hline & Nanocrystal & $\begin{array}{l}\text { Hot injection } \\
\text { Antisolvent recrystallization }\end{array}$ & {$[50,51,56]$} \\
\hline $\mathrm{Cs}_{2}\left(\mathrm{Ag}_{1-a} \mathrm{Bi}_{1-b}\right) \mathrm{Tl}_{x} \mathrm{Br}_{6}$ & Single crystal & Cooling crystallization & {$[57]$} \\
\hline $\mathrm{Cs}_{2} \mathrm{Ag}\left(\mathrm{Bi}_{1-x} \mathrm{M}_{x}\right) \mathrm{Br}_{6}(\mathrm{M}=\mathrm{In}, \mathrm{Sb})$ & Single crystal & Melt crystallization & {$[58]$} \\
\hline $\mathrm{Cs}_{2} \mathrm{AgBiI}_{6}$ & Nanocrystal & $\begin{array}{l}\text { Antisolvent recrystallization } \\
\text { Anion exchange }\end{array}$ & {$[50,51]$} \\
\hline $\mathrm{Cs}_{2} \mathrm{AgInCl}_{6}$ & $\begin{array}{l}\text { Single crystal } \\
\text { Powder }\end{array}$ & $\begin{array}{l}\text { Cooling crystallization } \\
\text { Precipitating from cold } \mathrm{HCl} \text { solution }\end{array}$ & [59-61] \\
\hline Mn-doped $\mathrm{Cs}_{2} \mathrm{AgInCl}_{6}$ & Microcrystal & Hot injection & {$[62]$} \\
\hline $\mathrm{Cs}_{2} \mathrm{NaBiI}_{6}$ & Microcrystal & Hydrothermal method & {$[64]$} \\
\hline $\mathrm{Cs}_{2} \mathrm{SnI}_{6}$ & $\begin{array}{l}\text { Microcrystal } \\
\text { Nanocrystal }\end{array}$ & Hot injection & [74-76] \\
\hline Bi-doped $\mathrm{Cs}_{2} \mathrm{SnCl}_{6}$ & Single crystal & Cooling crystallization & {$[77]$} \\
\hline \multirow[t]{2}{*}{$\mathrm{Cs}_{2} \mathrm{PdBr}_{6}$} & Single crystal & Cooling crystallization & {$[78]$} \\
\hline & Nanocrystal & Antisolvent recrystallization & [79] \\
\hline $\mathrm{Cs}_{2} \mathrm{PdI}_{6}$ & Nanocrystal & Anion exchange & [79] \\
\hline $\begin{array}{l}\mathrm{A}_{2} \mathrm{TiBr}_{6} \\
(\mathrm{~A}=\mathrm{K}, \mathrm{Rb}, \mathrm{Cs})\end{array}$ & Powder & Molten salt & {$[80]$} \\
\hline $\begin{array}{l}\mathrm{Cs}_{2} \mathrm{TiI}_{x} \mathrm{Br}_{6-x} \\
(x=0,2,4,6)\end{array}$ & Powder & Melt crystallization & {$[81]$} \\
\hline$(\mathrm{MA})_{2} \mathrm{KBiCl}_{6}$ & Powder & Evaporating $\mathrm{HCl}$ solution to dryness & {$[38]$} \\
\hline$(\mathrm{MA})_{2} \mathrm{TlBiBr}_{6}$ & Single crystal & Hydrothermal method & {$[82]$} \\
\hline$(\mathrm{MA})_{2} \mathrm{AgBiBr}_{6}$ & Powder & Evaporating $\mathrm{HBr}$ solution to dryness & {$[83]$} \\
\hline$(\mathrm{MA})_{2} \mathrm{AgSbI}_{6}$ & Powder & Melt crystallization & {$[84]$} \\
\hline$(\mathrm{MA})_{2} \mathrm{AgBiI}_{6}$ & Powder & Melt crystallization & {$[85]$} \\
\hline $\begin{array}{l}(\mathrm{MA})_{2} \mathrm{KGdCl}_{6} \\
(\mathrm{MA})_{2} \mathrm{KYCl}_{6}\end{array}$ & Powder & Evaporating $\mathrm{HCl}$ solution to dryness & {$[86]$} \\
\hline$(\mathrm{MA})_{2} \mathrm{AgInBr}_{6}$ & Single crystal & $\mathrm{MAPbBr}_{3}$-induced crystallization & {$[87]$} \\
\hline$(\mathrm{MA})_{2} \mathrm{SnI}_{6}$ & Powder & Mixed iodides & {$[88]$} \\
\hline
\end{tabular}

in cubic $\overline{F m} 3 \mathrm{~m}$ symmetry and shows light absorption at the visible range of the spectrum $[48,49,52]$. Woodward et al. [48] measured diffuse reflectance to reveal bandgaps of 2.19 and $2.77 \mathrm{eV}$ for $\mathrm{Cs}_{2} \mathrm{AgBiBr}_{6}$ and $\mathrm{Cs}_{2} \mathrm{AgBiCl}_{6}$, respectively, as shown in Fig. 2a. The band structure calculation indicates that the interaction between $\mathrm{Ag} 4 \mathrm{~d}$ orbitals and $3 \mathrm{p} / 4 \mathrm{p}$ orbitals of the halide ions modifies valence band, leading to an indirect bandgap. Both compounds are stable when exposed to air; however, $\mathrm{Cs}_{2} \mathrm{AgBiBr}_{6}$ degrades over a period of weeks when exposed to ambient air and light. Meanwhile, Karunadasa et al. [52] tried to synthesize highly thermal and moisture-stable $\mathrm{Cs}_{2} \mathrm{AgBiBr}_{6}$ single crystal with an indirect bandgap of $1.95 \mathrm{eV}$ and photoluminescence (PL) lifetime of $\sim 660 \mathrm{~ns}$, as shown in Fig. $2 \mathrm{~b}$, which is very encouraging for photovoltaic applications. Then, Giustino et al. [49] designed and synthesized $\mathrm{Cs}_{2} \mathrm{AgBiCl}_{6}$ with 
(a) 100

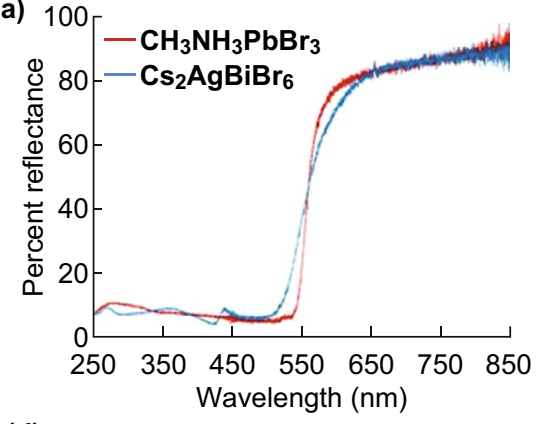

(d)

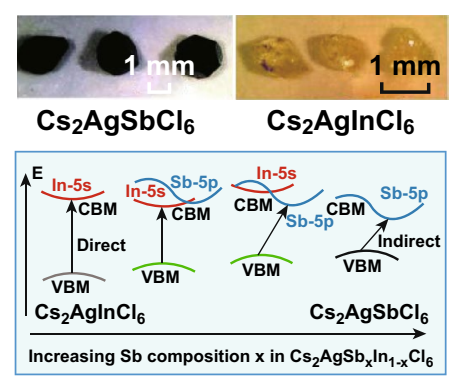

(b)

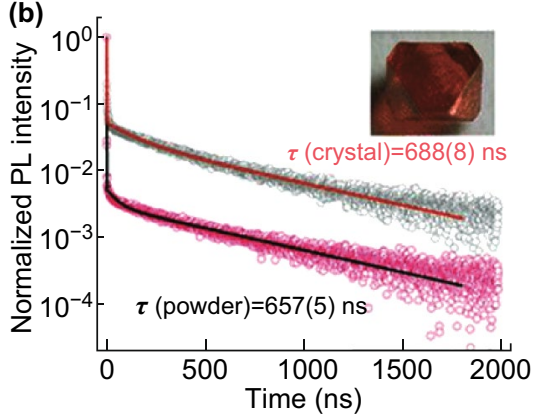

(e)

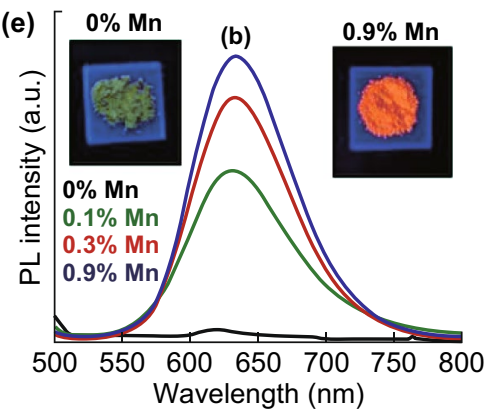

(c)

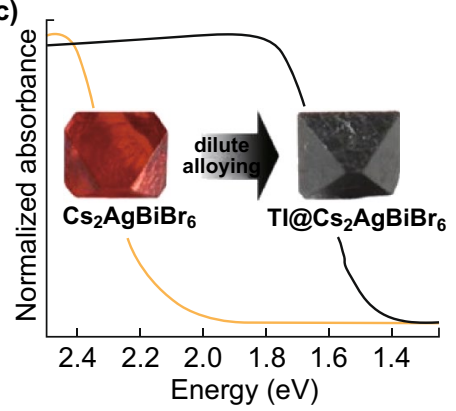

(f)

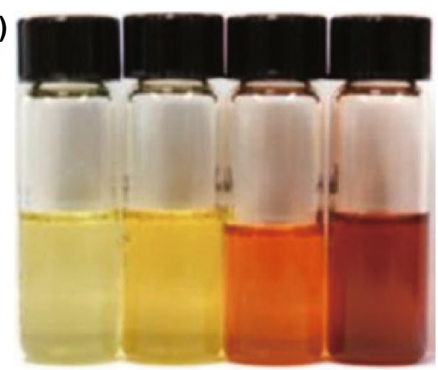

Fig. 2 a Diffuse reflectance spectra of $\mathrm{Cs}_{2} \mathrm{AgBiBr}_{6}$ and $\mathrm{CH}_{3} \mathrm{NH}_{3} \mathrm{PbBr}_{3}$. Reproduced with permission from Ref. [48]. b Time-resolved roomtemperature PL and fits for the PL decay time $(\tau)$ in powder and single-crystal samples. The inset is the photograph of a Cs $\mathrm{SgBiBr}_{6} \operatorname{single}$ crystal. Reproduced with permission from Ref. [52]. c Apparent bandgaps of $\mathrm{Cs}_{2} \mathrm{AgBiBr}_{6}$ and $\mathrm{Cs}_{2}\left(\mathrm{Ag}_{1-\mathrm{a}} \mathrm{Bi}_{1-\mathrm{b}}\right) \mathrm{TlxBr}_{6}(x=a+b=0.075)$ single crystals extracted by linear fits to $\alpha^{2}$ vs. E (direct gap) and $\alpha^{1 / 2}$ vs. E plots (indirect gap). Reproduced with permission from Ref. [57]. d Photographs of $\mathrm{Cs}_{2} \mathrm{AgSbCl}_{6}$ and $\mathrm{Cs}_{2} \mathrm{AgInCl}_{6}$ single crystals (top), and band diagram. A change in the character of the conduction band minimum $(\mathrm{CBM})$ from $\mathrm{s}$ orbital derived to $\mathrm{p}$ orbital derived while having the valence band maximum (VBM) primarily Ag-d states results in a transition from direct to indirect bandgap. Reproduced with permission from Ref. [59]. e PL spectra of Mn-doped $\mathrm{Cs}_{2} \mathrm{AgInCl}_{6}$ with different $\mathrm{Mn}$ contents, after excitation with $340 \mathrm{~nm}$ light. Insets show photographs of luminescence from powder samples under UV light. Reproduced with permission from Ref. [62]. f Photograph of dilute toluene solutions of $\mathrm{Cs}_{2} \mathrm{AgBiBr}_{6}, \mathrm{Cs}_{2} \mathrm{AgBiBr}_{5.2} \mathrm{I}_{0.8}, \mathrm{Cs}_{2} \mathrm{AgBiBr}_{1.6} \mathrm{I}_{4.4}$ and $\mathrm{Cs}_{2} \mathrm{AgBiI}_{6}$ nanocrystals. Reproduced with permission from Ref. [51]

bandgaps between 1.95 and $3.04 \mathrm{eV}$. However, the bandgap of $\mathrm{Cs}_{2} \mathrm{AgBiX}_{6}(\mathrm{X}=\mathrm{Cl}, \mathrm{Br})$ is indirect and slightly large, not ideal for thin-film photovoltaic applications. To engineer the bandgaps, Karunadasa et al. [52, 57] tried to incorporate $\mathrm{Tl}$ as a dilute impurity into their reported $\mathrm{Cs}_{2} \mathrm{AgBiBr}_{6}$ single crystals. After incorporating $\mathrm{Tl}$, the color changed to opaque black from translucent orange, which reflects the reduction of the bandgaps, as shown in Fig. 2c. The Tl content can be tuned across the series $\mathrm{Cs}_{2}\left(\mathrm{Ag}_{1-a} \mathrm{Bi}_{1-b}\right) \mathrm{Tl}_{\mathrm{x}} \mathrm{Br}_{6}$ $(0.003<x=a+b<0.075)$, and $\mathrm{Cs}_{2}\left(\mathrm{Ag}_{1-a} \mathrm{Bi}_{1-b}\right) \mathrm{Tl}_{\mathrm{x}} \mathrm{Br}_{6}$ $(x=0.075)$ displays low indirect and direct bandgaps of 1.40 and $1.57 \mathrm{eV}$, respectively. Importantly, time-resolved photoconductivity measurements reveal long-lived carriers with microsecond lifetimes in the alloyed material, suggesting that carriers can be efficiently extracted in a solar cell [53]. The alloyed perovskite is the first halide double perovskite to show comparable bandgap and carrier lifetime to those of $\mathrm{CH}_{3} \mathrm{NH}_{3} \mathrm{PbI}_{3}$, but unfortunately the content of $\mathrm{Tl}$ is still toxic [53, 57]. In 2017, Yan et al. [58] used $\mathrm{Cs}_{2} \mathrm{AgBiBr}_{6}$ as a host to engineer the bandgap through alloying of $\operatorname{In}^{3+}$ and $\mathrm{Sb}^{3+} . \mathrm{Cs}_{2} \mathrm{Ag}\left(\mathrm{Bi}_{1-x} \mathrm{M}_{x}\right) \mathrm{Br}_{6}(\mathrm{M}=\mathrm{In}, \mathrm{Sb})$ accommodates up to $75 \% \mathrm{In}^{3+}$ with increased bandgap, and up to $37.5 \% \mathrm{Sb}^{3+}$ with reduced bandgap, that is, enabling $\sim 0.41 \mathrm{eV}$ bandgap modulation through introduction of the two metals, with smallest value of $1.86 \mathrm{eV}$ for $\mathrm{Cs}_{2} \mathrm{Ag}\left(\mathrm{Bi}_{0.625} \mathrm{Sb}_{0.375}\right) \mathrm{Br}_{6}$. Band structure calculations indicate that opposite bandgap shift directions associated with $\mathrm{Sb} / \mathrm{In}$ substitution arise from different atomic configurations for these atoms. Similarly, McQueen et al. [59] designed indirect and direct bandgap transitions using alloy strategy, as shown in Fig. 2d. The synthesized $\mathrm{Cs}_{2} \mathrm{AgSbCl}_{6}$ and $\mathrm{Cs}_{2} \mathrm{AgInCl}_{6}$ single crystals have indirect and direct bandgaps, respectively. When increasing Sb composition $x$ in $\mathrm{Cs}_{2} \mathrm{AgSb}_{x} \mathrm{In}_{1-x} \mathrm{Cl}_{6}$, the compounds gradually transit from direct to indirect bandgap. Later on, Giustino et al. [60] identified that $\mathrm{Cs}_{2} \mathrm{InAgCl}_{6}$ has direct bandgap of $3.3 \mathrm{eV}$ and the compound is found to be photosensitive and turns reversibly from white to orange under ultraviolet (UV) illumination. Typically, $\mathrm{Cs}_{2} \mathrm{InAgCl}_{6}$ exhibits a wide bandgap 
which limits its application in the visible region. In 2018, Nag et al. [62] imparted the visible-light emission property in direct bandgap $\mathrm{Cs}_{2} \mathrm{AgInCl}_{6}$ by doping $\mathrm{Mn}^{2+}$ ions, as shown in Fig. 2e. $\mathrm{Cs}_{2} \mathrm{AgInCl}_{6}$ host absorbs UV light and then transfers the excitation energy to Mn d electrons. For $\mathrm{X}$-site in perovskites, the Bohr radii gradually increase from $F$ to I elements, resulting in increasing tightly bound nature and bandgaps [63]. Obviously, the $\mathrm{X}$ elements in the synthesized halide double perovskites are usually $\mathrm{Cl}$ or $\mathrm{Br}$, and the bandgaps are relatively large. Gamelin et al. [51] synthesized $\mathrm{Cs}_{2} \mathrm{AgBiX}_{6}(\mathrm{X}=\mathrm{Cl}, \mathrm{Br})$ colloidal nanocrystals by a hotinjection approach, which were converted to new materials including $\mathrm{Cs}_{2} \mathrm{AgBiI}_{6}$ with a narrow bandgap about $1.75 \mathrm{eV}$ through anion exchange. Figure $2 \mathrm{f}$ shows the photograph of dilute toluene solutions of (left to right) $\mathrm{Cs}_{2} \mathrm{AgBiBr}_{6}$, $\mathrm{Cs}_{2} \mathrm{AgBiBr}_{5.2} \mathrm{I}_{0.8}, \mathrm{Cs}_{2} \mathrm{AgBiBr}_{1.6} \mathrm{I}_{4.4}$ and $\mathrm{Cs}_{2} \mathrm{AgBiI}_{6}$ nanocrystals, and the dark red color of $\mathrm{Cs}_{2} \mathrm{AgBiI}_{6}$ reflects that the absorption extends throughout the visible region. Recently, Ma et al. [64] reported first time the synthesis of novel halide double perovskite material of $\mathrm{Cs}_{2} \mathrm{NaBiI}_{6}$ and determined its crystal structure by XRD and XPS tests and optical properties by UV-Vis absorption spectra. $\mathrm{Cs}_{2} \mathrm{NaBiI}_{6}$ has a low direct bandgap of $1.66 \mathrm{eV}$ and exhibits high stability against moisture and oxygen in ambient air.

To seek halide double perovskites theoretically, Zhang et al. [65-69] designed a series of all-inorganic halide double perovskites through first-principles calculations for the last 2 years. Photovoltaic-functionality-directed material screening process involves totally sixty-four candidate materials to identify $11 \mathrm{Sb}$ - and Bi-based optimal materials containing intrinsic thermodynamic stability, suitable bandgaps, small carrier effective masses and low excitons binding energies as promising photovoltaic materials. When the monovalent ion is $\mathrm{Tl}^{+}$or $\mathrm{In}^{+}$, the materials have direct bandgap, among which $\mathrm{Cs}_{2} \mathrm{InSbCl}_{6}$ and $\mathrm{Cs}_{2} \mathrm{InBiCl}_{6}$ have the bandgap about $1.0 \mathrm{eV}$, and show the theoretical maximum performance comparable to that of $\mathrm{CH}_{3} \mathrm{NH}_{3} \mathrm{PbI}_{3}$. However, the $\mathrm{Tl}$ is still toxic and the $\mathrm{In}^{+}$is unstable by spontaneous oxidation into $\mathrm{In}^{3+}$ [70]. They simultaneously designed trivalent $\mathrm{In}^{3+}$ ion with monovalent $\mathrm{Ag}^{+}$or $\mathrm{Cu}^{+}$ion to find halide double perovskites [69]. Among them, $\mathrm{Rb}_{2} \mathrm{CuInCl}_{6}, \mathrm{Rb}_{2} \mathrm{AgInBr}_{6}$ and $\mathrm{Cs}_{2} \mathrm{AgInBr}_{6}$ have direct bandgaps of $1.36,1.46$ and $1.50 \mathrm{eV}$, respectively, and theoretical spectroscopic limited maximal efficiency comparable to $\mathrm{CH}_{3} \mathrm{NH}_{3} \mathrm{PbI}_{3}$.

It is noteworthy that there is another type of halide double perovskite as vacancy-ordered $\mathrm{A}_{2} \mathrm{M}(\mathrm{IV}) \mathrm{X}_{6}(\mathrm{M}(\mathrm{IV})=\mathrm{Sn}$,
Ti, Pd, Te, etc.), which not only proposes direct bandgaps, but also intrinsic stability and non-/low toxicity [71-73]. In 2014, Kanatzidis et al. [74] prepared $\mathrm{Cs}_{2} \mathrm{SnI}_{6}$ microcrystal by a hot-injection method. $\mathrm{Cs}_{2} \mathrm{SnI}_{6}$ nanocrystal was prepared with controlled shapes by the same method [75, 76]. The bandgap of the $\mathrm{Cs}_{2} \mathrm{SnI}_{6}$ was found to be varied in the range of 1.36-1.67 eV. Quantum confinement effect has been observed for the nanoparticles of dimension below $8 \mathrm{~nm}$. In 2018, Tang et al. [77] fabricated Bi-doped $\mathrm{Cs}_{2} \mathrm{SnCl}_{6}$ single crystals, where the photoluminescence was observed from $\mathrm{Bi}^{3+}$ ions. In 2017, Snaith et al. [78] reported $\mathrm{Cs}_{2} \mathrm{PdBr}_{6}$ single crystal, which exhibits long-lived photoluminescence, direct bandgap of $1.6 \mathrm{eV}$ and long-term stability. In 2018, Kuang et al. [79] used antisolvent recrystallization method to prepare $\mathrm{Cs}_{2} \mathrm{PdBr}_{6}$ nanocrystals with an average particle diameter of $2.8 \mathrm{~nm}$. Such $\mathrm{Cs}_{2} \mathrm{PdBr}_{6}$ nanocrystals not only display high stability against light illumination (one sun for more than $1000 \mathrm{~h}$ ), moisture (70\% for 2 months) and high temperature $\left(120^{\circ} \mathrm{C}\right.$ for $\left.600 \mathrm{~h}\right)$ conditions but also possess intriguing optical and ultrafast photophysical properties with a narrow direct bandgap of $1.69 \mathrm{eV}$. Further, a fast anion exchange method is adopted to prepare the $\mathrm{Cs}_{2} \mathrm{PdI}_{6}$ nanocrystals. Another Ti-based vacancy-ordered halide double perovskites can start back in the early 1960s, and $\mathrm{K}_{2} \mathrm{TiBr}_{6}, \mathrm{Rb}_{2} \mathrm{TiBr}_{6}$ and $\mathrm{Cs}_{2} \mathrm{TiBr}_{6}$ were prepared by using fused $\mathrm{SbBr}_{3}$ as the solvent [80]. However, the studies of them in optoelectronics have not been performed until 2018, and Zhou et al. [81] synthesized a series of $\mathrm{Cs}_{2} \mathrm{TiI}_{x} \mathrm{Br}_{6-x}$ $(x=0,2,4,6)$ powers using the melt crystallization method, of which the bandgap can be tuned continuously from 1.02 to $1.78 \mathrm{eV}$. The present vacancy-ordered halide double perovskites possess several desirable properties, including ultrastability, suitable direct bandgap, excellent optical absorption and benign defect.

\subsection{Hybrid Halide Double Perovskites}

To date, there have been synthesized nine hybrid halide double perovskites to the best of our knowledge, which are $(\mathrm{MA})_{2} \mathrm{KBiCl}_{6}$ [38], $(\mathrm{MA})_{2} \mathrm{TlBiBr}_{6}$ [82], $(\mathrm{MA})_{2} \mathrm{AgBiBr}_{6}$ [83], (MA) ${ }_{2} \mathrm{AgSbI}_{6}$ [84], (MA) ${ }_{2} \mathrm{AgBiI}_{6}$ [85], (MA) ${ }_{2} \mathrm{KGdCl}_{6}$ [86], (MA) ${ }_{2} \mathrm{KYCl}_{6}$ [86], (MA) ${ }_{2} \mathrm{AgInBr}_{6}$ [87], and (MA) $)_{2} \mathrm{SnI}_{6}$ [88], as listed in Table 1. In 2016, the first hybrid halide double perovskite (MA) ${ }_{2} \mathrm{KBiCl}_{6}$ was synthesized by evaporating $\mathrm{HCl}$ solution to dryness [38]. In the Tauc plot from 
the reflectance spectrum, there are two edges with values of 3.04 and $3.37 \mathrm{eV}$ in Fig. 3a, in accordance with the theoretically calculated indirect bandgap of $3.02 \mathrm{eV}$ and direct bandgap of $3.15 \mathrm{eV}$ as shown in Fig. 3b, c. Further, density functional theory screening of $(\mathrm{MA})_{2} \mathrm{MBiX}_{6}(\mathrm{M}=\mathrm{K}$, $\mathrm{Cu}, \mathrm{Ag}, \mathrm{Tl} ; \mathrm{X}=\mathrm{Cl}, \mathrm{Br}$, I) shows that systems with bandgaps similar to those of the $\mathrm{CH}_{3} \mathrm{NH}_{3} \mathrm{PbX}_{3}$ lead compounds can be expected for $\mathrm{M}=\mathrm{Cu}, \mathrm{Ag}$, Tl. Motivated by these findings, (MA) ${ }_{2} \mathrm{TlBiBr}_{6}$, isoelectronic with $\mathrm{CH}_{3} \mathrm{NH}_{3} \mathrm{PbBr}_{3}$, was synthesized and found to have a direct bandgap of $2.16 \mathrm{eV}$, as shown in Fig. 3d [82]. However, despite its interesting electronic properties, the severe toxicity of $\mathrm{Tl}$ precludes (MA) ${ }_{2} \mathrm{TlBiBr}_{6}$ from being a practical alternative to the $\mathrm{Pb}$ analog. Subsequently, they synthesized a hybrid halide double perovskite, $(\mathrm{MA})_{2} \mathrm{AgBiBr}_{6}$, that has a low indirect bandgap of $2.02 \mathrm{eV}$ and is relatively stable and nontoxic [83]. The material is stable in air and moisture and exhibits higher decomposition temperature than that of $\mathrm{MAPbBr}_{3}$. In 2017, the same group synthesized (MA) ${ }_{2} \mathrm{AgSbI}_{6}$ [84] and (MA) ${ }_{2} \mathrm{AgBiI}_{6}[85]$ with indirect bandgap of $\sim 2 \mathrm{eV}$ and exhibited high stability in air, as the XRD patterns shown in Fig. 3e, f. Though $\mathrm{Sb}$ and $\mathrm{Bi}$ are in the same group, there are still some differences between them. Compared with
$\mathrm{Bi}$ atom, $\mathrm{Sb}$ atom has a smaller mass and ion radius and the smaller ion radius of Sb leads to structural distortion of (MA) ${ }_{2} \mathrm{AgSbI}_{6}$, while the structure of (MA) $)_{2} \mathrm{AgBiI}_{6}$ is the orthogonal phase. Besides, due to the seriously relativistic effects in heavy metal atom $\mathrm{Bi}$, the impact of spin-orbit coupling on bandgap of (MA) ${ }_{2} \mathrm{AgBiI}_{6}$ is more pronounced. Simultaneously, (MA) ${ }_{2} \mathrm{KGdCl}_{6}$ and (MA) ${ }_{2} \mathrm{KYCl}_{6}$ have been synthesized by a solution evaporation method, which adopt a rhombohedral structure with R3 m symmetry [86]. Both phases exhibit a rhombohedral-to-cubic phase transition on heating to $\sim 435 \mathrm{~K}$ as shown in Fig. $3 \mathrm{~g}$. Density functional calculations on the rhombohedral phase indicate that both materials have large direct bandgaps about $5 \mathrm{eV}$ and mechanical stability. In 2018, (MA) ${ }_{2} \mathrm{AgInBr}_{6}$ single crystal [87], as shown in Fig. 3h, is obtained through the use of $\mathrm{Pb}^{2+}$ (from $\mathrm{CH}_{3} \mathrm{NH}_{3} \mathrm{PbBr}_{3}$ ) to modulate the soluble intermediates and force the formation. In the same year, $(\mathrm{MA})_{2} \mathrm{SnI}_{6}$ powder was obtained by mixing $\mathrm{SnI}_{4}$ with $\mathrm{CH}_{3} \mathrm{NH}_{3} \mathrm{I}$ powder at room temperature [88]. The powder was evaporated in a tungsten boat at $120{ }^{\circ} \mathrm{C}$ in a vacuum chamber to deposit the (MA) ${ }_{2} \mathrm{SnI}_{6}$ films. The films have a direct bandgap of $1.81 \mathrm{eV}$ with a strong absorption coefficient of $\sim 7 \times 10^{4} \mathrm{~cm}^{-1}$. In addition, the films were $\mathrm{n}$ type with a carrier concentration
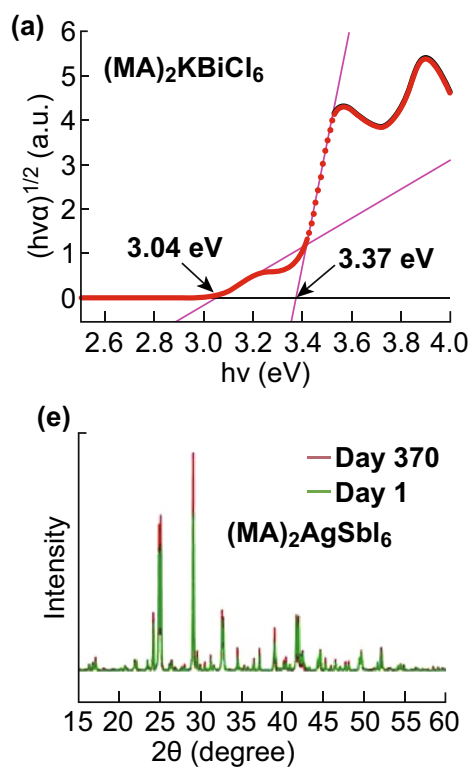

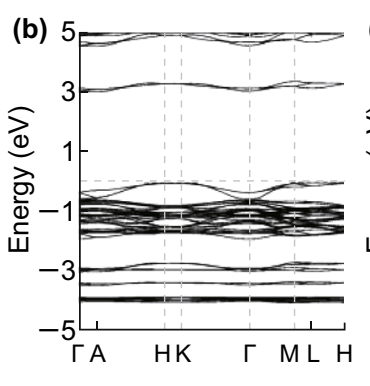

(f)

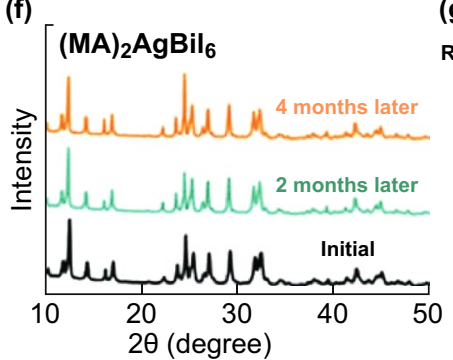

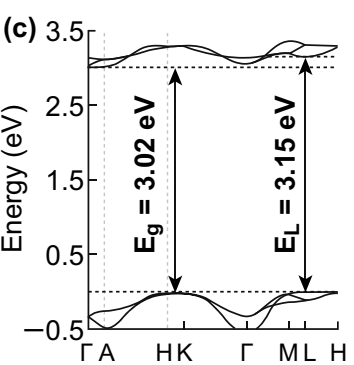

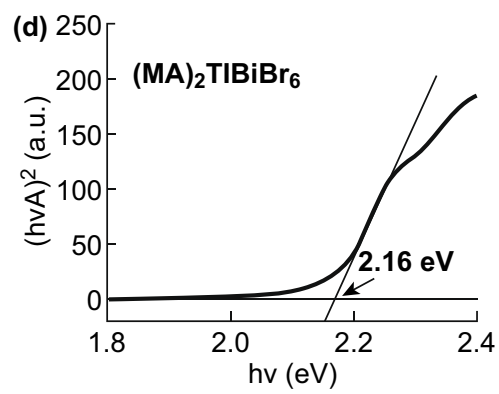

(g) $\left(\mathrm{CH}_{3} \mathrm{NH}_{3}\right)_{2} \mathrm{KM}^{1 ! \prime} \mathrm{Cl}_{6}$

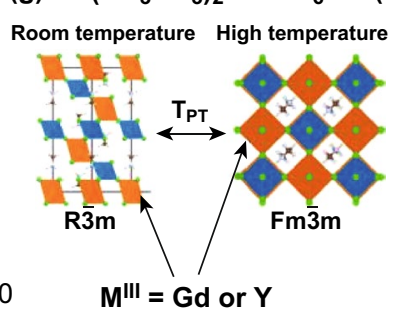

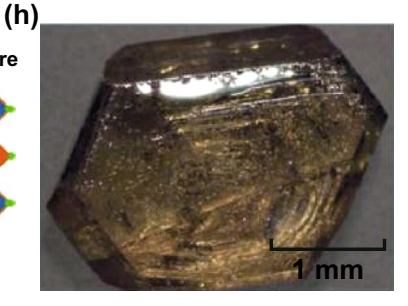

Fig. 3 a Tauc plot (assumed indirect bandgap), b-c calculated band structure of (MA) ${ }_{2} \mathrm{KBiCl}_{6}$ and the enlarged view of the band structure near the bandgap. Reproduced with permission from Ref. [38]. d Tauc plot (assumed direct bandgap) of (MA) ${ }_{2} \mathrm{TIBiBr}_{6}$. Reproduced with permission from Ref. [82]. e XRD patterns of fresh (MA) ${ }_{2} \mathrm{AgSbI}_{6}$ compared to (MA) ${ }_{2} \mathrm{AgSbI}_{6}$ after 370 days of exposure to air. Reproduced with permission from Ref. [84]. f Air stability of (MA) ${ }_{2} \mathrm{AgBiI}_{6}$. Reproduced with permission from Ref. [85]. $\mathbf{g}$ Schematic illustration of rhombohedral-to-cubic phase transition on high-temperature heating for $(\mathrm{MA})_{2} \mathrm{KGdCl}_{6}$ and $(\mathrm{MA})_{2} \mathrm{KYCl}_{6}$. Reproduced with permission from Ref [86]. $\mathbf{h}$ Photograph of a $(\mathrm{MA})_{2} \mathrm{AgBiBr}_{6}$ single crystal. Reproduced with permission from Ref. [87] 
of $\sim 2 \times 10^{15} \mathrm{~cm}^{-3}$ and an electron mobility of $\sim 3 \mathrm{~cm}^{2} / \mathrm{V} / \mathrm{s}$. Moreover, the conductivity was increased by a factor of 4 under simulated solar illumination $\left(100 \mathrm{~mW} \mathrm{~cm}^{-2}\right)$. These results indicate that (MA) ${ }_{2} \mathrm{SnI}_{6}$ is a lead-free optical semiconductor suitable for solar cell applications. The synthesized hybrid halide double perovskites indicate substantially better stability, unlike $\mathrm{CH}_{3} \mathrm{NH}_{3} \mathrm{PbI}_{3}$. However, to the best of our knowledge, there are no reports about applications of hybrid halide double perovskites.

\section{Optoelectronic Applications}

\subsection{Photodetectors}

In 2017, Tang et al. [61] successfully prepared high-quality $\mathrm{Cs}_{2} \mathrm{AgInCl}_{6}$ single crystals with a low trap state density $\left((8.6 \pm 1.9) \times 10^{8} \mathrm{~cm}^{-3}\right)$ by a hydrothermal method, which were further applied in UV detectors. The obtained results experimentally verified the existence of parity-forbidden transition [89] and identified that the oxygen was effective on the optical properties. By eliminating oxygen contamination in vacuum, $\mathrm{Cs}_{2} \mathrm{AgInCl}_{6}$ single crystal-based UV detector showed best performance with visible blind, high ON-OFF ratio $(\sim 500)$, fast photoresponse $(\sim 1 \mathrm{~ms})$, low dark current ( $\sim 10 \mathrm{pA}$ at $5 \mathrm{~V}$ bias) and high detectivity ( 1012 Jones). If the $\mathrm{Cl}$ is replaced by $\mathrm{Br}$ in $\mathrm{Cs}_{2} \mathrm{AgInX}_{6}$ compounds, the bandgaps reduce and absorption range can be extended to visible region. Shi et al. [90] used a one-step spin-coating method to prepare $\mathrm{Cs}_{2} \mathrm{AgBiBr}_{6}$ thin films for photodetectors. The device exhibits high responsivity of 7.01 $\mathrm{A} \mathrm{W}^{-1}$, ON-OFF ratio of $2.16 \times 10^{4}$, specific detectivity of $5.66 \times 10^{11}$ Jones, EQE of $2146 \%$ and demonstrates remarkable stability against the water and oxygen degradation. Wang et al. [91] fabricated highly efficient and stable selfpowered UV and deep-blue detector based on $\mathrm{Cs}_{2} \mathrm{AgBiBr}_{6} /$ $\mathrm{SnO}_{2}$ heterojunction, as shown in Fig. 4a. The photogenerated carriers in $\mathrm{Cs}_{2} \mathrm{AgBiBr}_{6}$ film can be separated at the $\mathrm{Cs}_{2} \mathrm{AgBiBr}_{6} / \mathrm{SnO}_{2}$ heterojunction interface by its built-in field, as illustrated in Fig. 4b. The device is self-powered with two responsivity peaks at 350 and $435 \mathrm{~nm}$, which is suitable for UV (320-400 nm) and deep-blue light detection, as shown in Fig. $4 \mathrm{c}$. A high responsivity of $0.11 \mathrm{~A} \mathrm{~W}^{-1}$ at $350 \mathrm{~nm}$ and a quick response time of less than $3 \mathrm{~ms}$ are obtained, which are significantly higher than those of other semiconductor oxide heterojunction-based UV detectors.
More importantly, the photocurrent shows no noticeable degradation after more than 6 months of storage in ambient conditions without encapsulation, as shown in Fig. 4d. In addition, the aforementioned vacancy-ordered double perovskites of $\mathrm{Cs}_{2} \mathrm{PdBr}_{6}$ single crystal and $\mathrm{Cs}_{2} \mathrm{SnI}_{6}$ nanocrystal were successfully applied in stable and fast photodetectors $[75,78]$. Consequently, the halide double perovskite-based photodetectors displayed high efficiency and stability and environmental friendliness, which are potential alternatives for practical applications.

\subsection{X-ray Detectors}

In 2017, Tang et al. [54] also prepared $\mathrm{Cs}_{2} \mathrm{AgBiBr}_{6}$ single crystals by controlling cooling rate in a solution for sensitive $\mathrm{X}$-ray detectors with a low detection limit. The $\mathrm{Cs}_{2} \mathrm{AgBiBr}_{6}$ single crystals can directly convert $\mathrm{X}$-rays into electrical signals due to the high average atomic number, high carrier drift length per unit electric field, low ionization energy and high resistivity. The optimized device exhibited high sensitivity of $105 \mu \mathrm{C} / \mathrm{Gyair} / \mathrm{cm}^{2}$, low detection limit of 59.7 nGyair s $^{-1}$ under an external bias of $5 \mathrm{~V}$ and demonstrated long-term operational stability, as shown in Fig. 5a, b, all of which are crucial for potential applications in X-ray security screening systems and medical diagnostics. Subsequently, $\mathrm{Yu}$ et al. [92] used composite films of $\mathrm{Cs}_{2} \mathrm{AgBiBr}_{6}$ embedded in a polymer matrix for X-ray detectors. The polymer with hydroxyl functional groups can greatly improve the uniformity of the composite films, and large area dense films can be obtained by a simple drop-casting process. X-ray detectors based on the composite films exhibit a sensitivity of $40 \mu \mathrm{C} / \mathrm{Gyair} / \mathrm{cm}^{2}$ under an external bias of $400 \mathrm{~V}$, as shown in Fig. 5c, and tolerate a 5\% tensile/compressive strain in the composite films without performance degradation. Pixelated X-ray detectors fabricated on the same composite film can realize X-ray imaging and resolve a proof-of-concept geometric pattern. Recently, Tang et al. [93] have used lanthanide series as trivalent metals to obtain highly stable halide double perovskites $\left(\mathrm{Cs}_{2} \mathrm{NaLnCl}_{6}, \mathrm{Ln}=\mathrm{Tb}\right.$ or $\left.\mathrm{Eu}\right)$ with high scintillation light yield. The crystals exhibit typical $\mathrm{f}-\mathrm{f}$ transitions of lanthanide cations, while $\mathrm{Cs}_{2} \mathrm{NaTbCl}_{6}$ exhibits strong green photoluminescence and $\mathrm{Cs}_{2} \mathrm{NaEuCl}_{6}$ exhibits red photoluminescence. Under $\mathrm{X}$-ray radiations, the light yield of $\mathrm{Cs}_{2} \mathrm{NaTbCl}_{6}$ reaches 46,600 photons $\mathrm{MeV}^{-1}$, much higher than that of the commercially used $(\mathrm{Lu}, \mathrm{Y})_{2} \mathrm{SiO}_{5}: \mathrm{Ce}^{3+}$ 
(a)

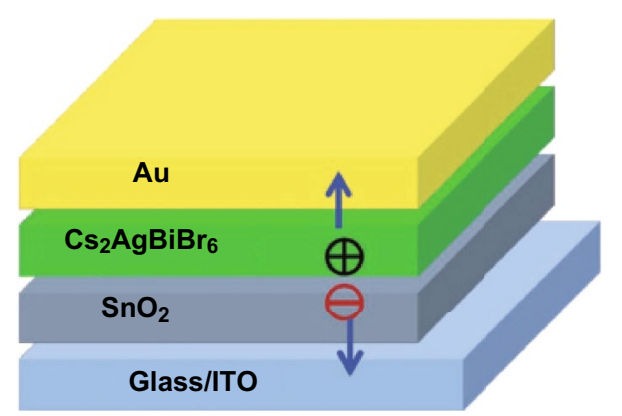

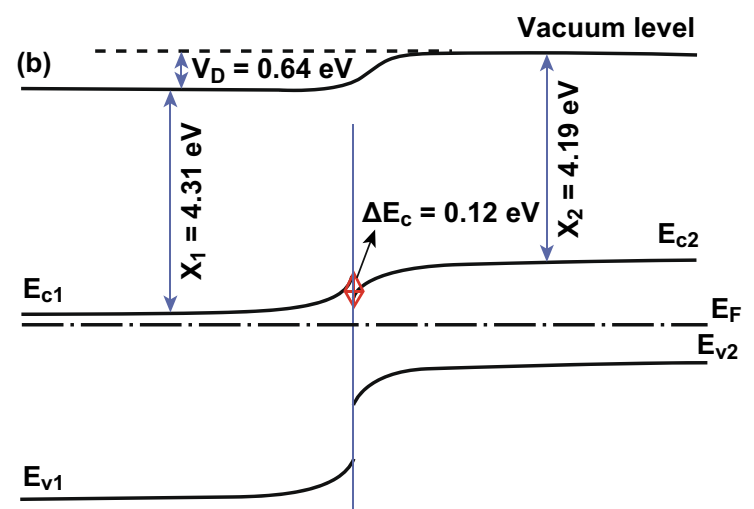

$\mathrm{SnO}_{2}$
$\mathrm{Cs}_{2} \mathrm{AgBiBr}_{6}$

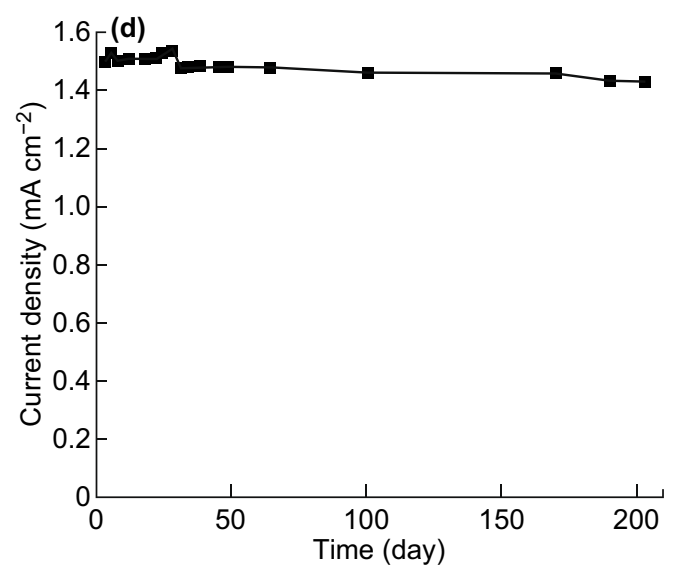

Fig. 4 a Configuration diagram of $\mathrm{Cs}_{2} \mathrm{AgBiBr}_{6}$-based photodetector. b Band scheme diagram of $\mathrm{Cs}_{2} \mathrm{AgBiBr}_{6} / \mathrm{SnO}_{2}$ heterojunction. $\mathbf{c}$ Responsivity of photodetector at zero bias. $\mathbf{d}$ Long-term stability test of $\mathrm{Cs}_{2} \mathrm{AgBiBr}_{6}$-based photodetector. Reproduced with permission from Ref. [91]

crystals (LYSO, 28,500 photons $\mathrm{MeV}^{-1}$ ), as shown in Fig. 5d. Lanthanide-based halide double perovskites open up a new route toward radiation detections and potential medical imaging.

\subsection{Photocatalyst}

In 2018, Kuang et al. [56] fabricated $\mathrm{Cs}_{2} \mathrm{AgBiBr}_{6}$ nanocrystals (NCs) via a simple hot-injection method for photocatalytic $\mathrm{CO}_{2}$ reduction. The $\mathrm{Cs}_{2} \mathrm{AgBiBr}_{6} \mathrm{NCs}$ can maintain their structure stability in low-polarity solutions (up to 3 weeks) and phase uniformity against $55 \%$ relative humidity for 90 days, light-soaking stability toward $70 \mathrm{~mW} \mathrm{~cm}^{-2}$ for $500 \mathrm{~h}$ or $100^{\circ} \mathrm{C}$ heating for $300 \mathrm{~h}$, thus declaring the impressive stability in moisture, light and temperature. Photocatalytic $\mathrm{CO}_{2}$ was conducted in ethyl acetate in a Pyrex glass bottle under simulated solar light (AM 1.5G, $150 \mathrm{~mW} \mathrm{~cm}^{-2}$ ) illumination. After the constant irradiation for $6 \mathrm{~h}$, the pristine $\mathrm{Cs}_{2} \mathrm{AgBiBr}_{6} \mathrm{NCs}$ could afford the evolution of $\mathrm{CO}$ and $\mathrm{CH}_{4}$ with 5.5 and $0.65 \mu \mathrm{mol} \mathrm{g}{ }^{-1}$, respectively. Meanwhile, the electron consumption attained $16.2 \mu \mathrm{mol} \mathrm{g}^{-1}$, as shown in Fig. 6a. On the contrary, the washed $\mathrm{Cs}_{2} \mathrm{AgBiBr}_{6}$ NCs have boosted the evolution of $\mathrm{R}(\mathrm{CO})$ and $\mathrm{R}\left(\mathrm{CH}_{4}\right)$ to 14.1 and $9.6 \mu \mathrm{mol} \mathrm{g}{ }^{-1}$, presenting a 6.5 -fold enhancement in the electron consumption. A tentative mechanism for the photocatalytic $\mathrm{CO}_{2}$ reduction over the $\mathrm{Cs}_{2} \mathrm{AgBiBr}_{6} \mathrm{NCs}$ is proposed in Fig. 6b, in which the $\mathrm{Cs}_{2} \mathrm{AgBiBr}_{6} \mathrm{NCs}_{\text {have a }}$ suitable conduction band to drive $\mathrm{CO}_{2}$ reduction. The timedependent evolution of $\mathrm{CO}$ and $\mathrm{CH}_{4}$ using the as-prepared and -washed NCs by absolute ethanol as photocatalysts under light irradiation is shown in Fig. 6c, where the evolution of $\mathrm{CO}$ and $\mathrm{CH}_{4}$ rose nearly linearly with irradiation time and the washed NCs exhibited higher efficiency for $\mathrm{CO}_{2}$ conversion. Therefore, the novel $\mathrm{Cs}_{2} \mathrm{AgBiBr}_{6} \mathrm{NCs}$ were successfully used to conduct the $\mathrm{CO}_{2}$ reduction reactions with 

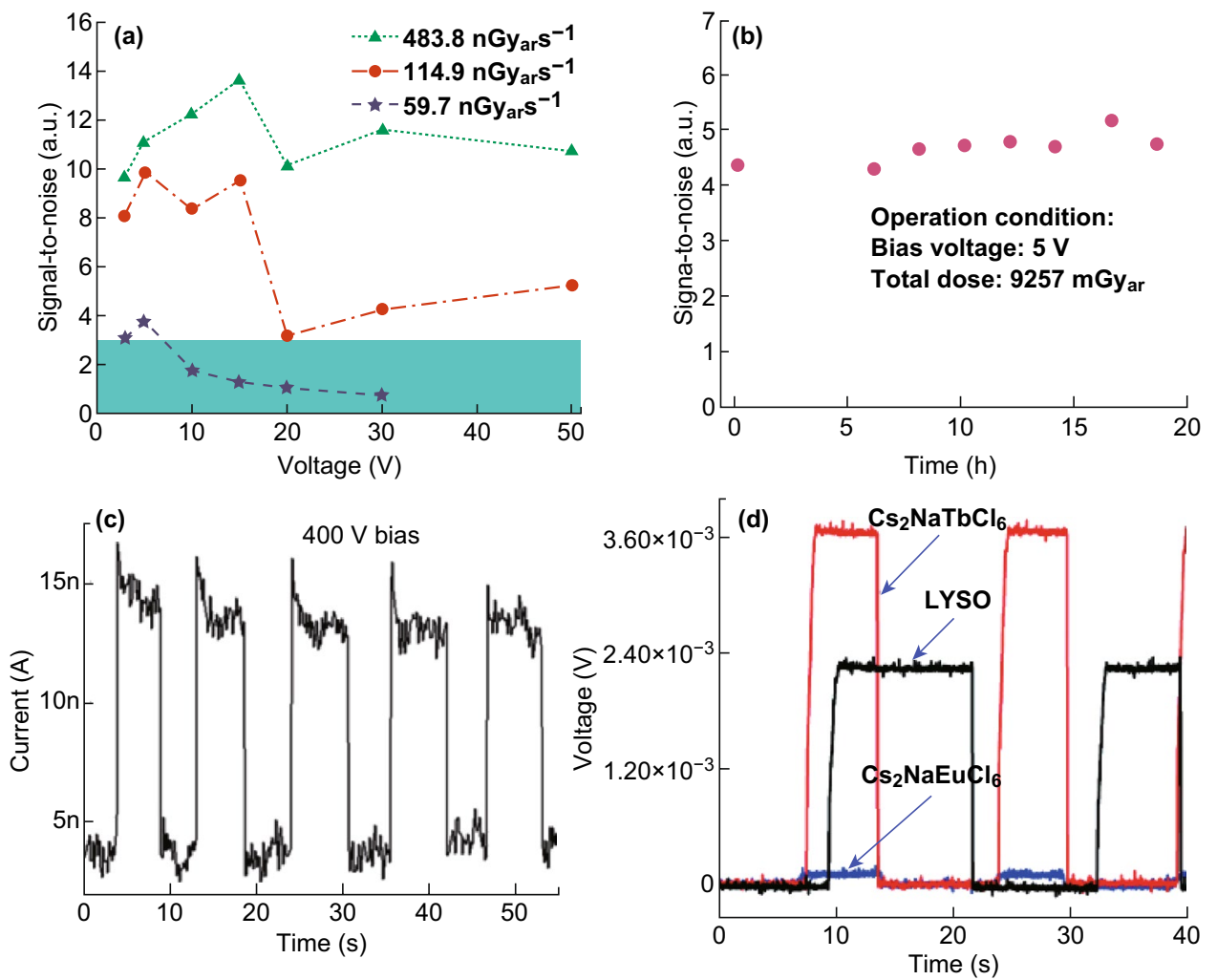

Fig. 5 a Signal-to-noise ratio of the device derived by calculating the standard deviation of the X-ray photocurrent. The red dashed line represents a SNR of 3, and thus the detection limit is $59.7 \mathrm{nGyair} \mathrm{s}^{-1}$ at $5 \mathrm{~V}$ bias, as indicated by the purple star surrounded by the red dashed circle. b Operational stability of our $\mathrm{Cs}_{2} \mathrm{AgBiBr}_{6}$ single-crystal X-ray detector. Testing conditions: continued $138.7 \mu \mathrm{Gyair} \mathrm{s}^{-1} \mathrm{X}$-ray irradiation with constant $5 \mathrm{~V}$ bias, tested in ambient air without any encapsulation. Reproduced with permission from Ref. [54]. c Transient responses of the detector at a constant $400 \mathrm{~V}$. Reproduced with permission [92]. d The generated voltage of multiplier tubes by scintillation light of $\mathrm{Cs}_{2} \mathrm{NaTbCl}_{6}$ (red line), $\mathrm{Cs}_{2} \mathrm{NaEuCl}_{6}$ (blue line) and $(\mathrm{Lu}, \mathrm{Y})_{2} \mathrm{SiO}_{5}: \mathrm{Ce}^{3+}$ (LYSO, black line), respectively (color online). Reproduced with permission from Ref. [93]. (Color figure online)

high selectivity and stability, which hold great potential in the further photochemical applications.

\subsection{LEDs}

Tang et al. [77] used the synthesized Bi-doped $\mathrm{Cs}_{2} \mathrm{SnCl}_{6}$ as blue emissive phosphors, where $\mathrm{Bi}^{3+}$ is the luminescent dopant. Hybrid density functional theory calculations suggest the preferred formation of $\left[\mathrm{Bi}_{\mathrm{Sn}}+\mathrm{V}_{\mathrm{Cl}}\right]$ defect complex, responsible for the optical absorption and the associated blue emission. The Bi-doped $\mathrm{Cs}_{2} \mathrm{SnCl}_{6}$ also shows impressive thermal and water stability due to its inorganic nature and the formation of protective BiOCl layer. A significant boost of the photoluminescence (emission peak: $455 \mathrm{~nm}$, PLQY: 78.9\%) was observed upon doping. This is the highest PLQY ever reported for all-inorganic lead-free perovskites and even comparable to the highest value of lead perovskites with blue emissions. Bi-doped $\mathrm{Cs}_{2} \mathrm{SnCl}_{6}$ showed great potential as blue phosphors, and its LED exhibited a warm white high light emission with a correlated color temperature of $4486 \mathrm{~K}$ and a Commission Internationale de I'Eclairage coordinate of $(0.36 ; 0.37)$ when integrated with yellow phosphor. Recently, Tang et al. [94] broke the parity-forbidden transition of $\mathrm{Cs}_{2} \mathrm{AgInCl}_{6}$ by alloying $\mathrm{Na}^{+}$cations, which leads to efficient white emission via radiative recombination of self-trapped excitons. The $\mathrm{Bi}^{3+}$ incorporation is believed to improve crystal perfection and promote exciton localization [95]. The optimally alloyed $\mathrm{Cs}_{2}\left(\mathrm{Ag}_{0.60} \mathrm{Na}_{0.40}\right) \mathrm{InCl}_{6}$ with $0.04 \% \mathrm{Bi}^{3+}$ doping emits warm white light with $(86 \pm 5) \%$ quantum efficiency and works for over $1000 \mathrm{~h}$. Therefore, halide double perovskites hold great potential for display and lighting applications and merit further study to realize their full potential. 

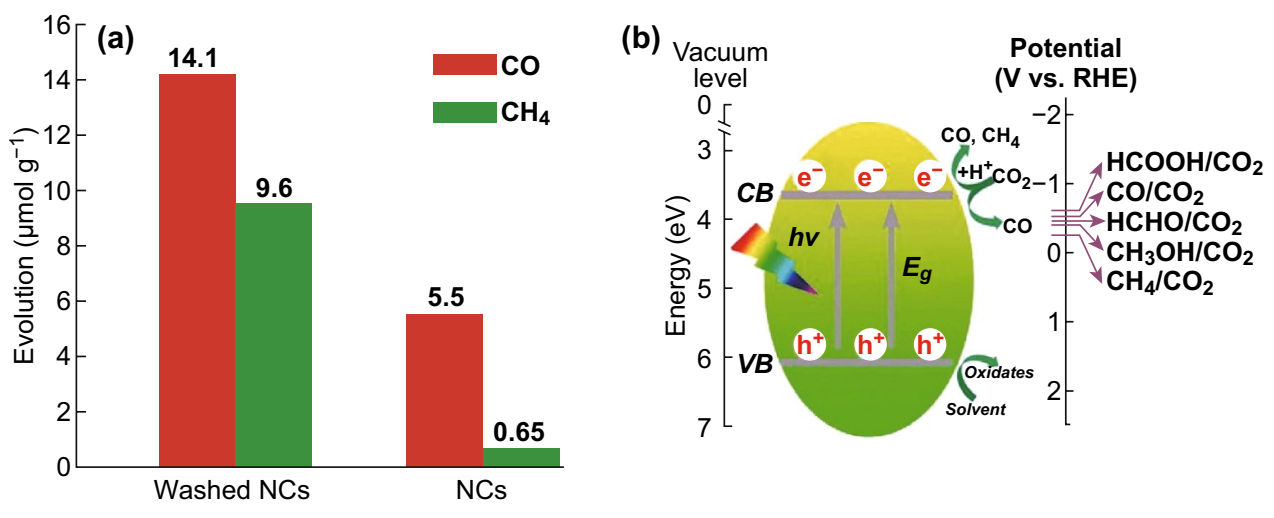

(c)

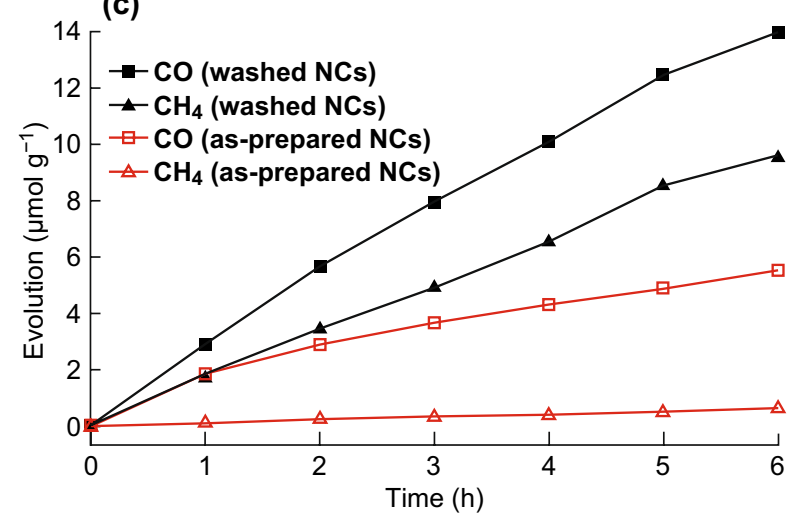

Fig. 6 a Comparison of photocatalytic $\mathrm{CO}_{2}$ reduction performance of the as-prepared $\mathrm{Cs}_{2} \mathrm{AgBiBr}_{6} \mathrm{NCs}$ and washed NCs. b Schematic diagram of the photoreduction of $\mathrm{CO}_{2}$ on the surface of $\mathrm{Cs}_{2} \mathrm{AgBiBr}_{6} \mathrm{NCs}$. $\mathbf{c}$ Time course of $\mathrm{CO}$ and $\mathrm{CH}_{4}$ evolutions over as-prepared and -washed $\mathrm{Cs}_{2} \mathrm{AgBiBr}_{6} \mathrm{NCs}$. Reproduced with permission from Ref. [56]

\subsection{Solar Cells}

To date, $\mathrm{Cs}_{2} \mathrm{AgBiBr}_{6}$ is most applied in halide double perovskite-based solar cells [96-100]. In 2017, Bein et al. [96] fabricated $\mathrm{Cs}_{2} \mathrm{AgBiBr}_{6}$ films by a spin-coating method and incorporated them into solar cells for the first time. After optimized synthesis conditions, the $\mathrm{Cs}_{2} \mathrm{AgBiBr}_{6}$-based solar cells revealed power conversion efficiency (PCE) of $2.43 \%$ and excellent stability upon exposure without encapsulation. Inadequately, there is a thick agglomerated morphology of the $\mathrm{Cs}_{2} \mathrm{AgBiBr}_{6}$ films with micrometer-sized grains on the surface, and the hysteresis of the devices is serious. In 2018, Wang et al. [97] developed planar heterojunction solar cells with high-quality $\mathrm{Cs}_{2} \mathrm{AgBiBr}_{6}$ film by low-pressure-assisted solution processing under ambient conditions, as shown in Fig. 7a, b, borrowing $\mathrm{Cs}_{2} \mathrm{AgBiBr}_{6} / \mathrm{SnO}_{2}$ heterojunction from their reported detectors [91]. Orange $\mathrm{Cs}_{2} \mathrm{AgBiBr}_{6}$ powder was dissolved in DMSO solution to form a light yellow transparent solution and then fabricate the film using spin-coating technique, as presented in Fig. 7a. The spin-coated film was quickly moved to a low-pressure chamber pumped to $20 \mathrm{~Pa}$, in which the transparent film would gradually turn to light yellow, as shown in Fig. 7b. Next, the as-prepared film was annealed and attained smooth morphology as shown in Fig. 7d. The optimized $\mathrm{Cs}_{2} \mathrm{AgBiBr}_{6}$ film achieved $1.44 \%$ PCE of the solar cells with P3HT hole conductor layer. On the contrary, the traditional thermal annealing method generated rough $\mathrm{Cs}_{2} \mathrm{AgBiBr}_{6}$ film in Fig. 7c, and the corresponding devices usually showed a poor PCE $(<0.1 \%)$. Furthermore, these devices also showed hysteresis phenomenon. Wu et al. [98] used anti-solvent dropping technology and post-annealing process to realize high-quality $\mathrm{Cs}_{2} \mathrm{AgBiBr}_{6}$ film with ultra-smooth morphology, microsized grains and high crystallinity (shown in Fig. 7e), which was applied in inverted planar heterojunction solar cells. The device shows PCE up to $2.23 \%$ with free hysteresis. Subsequently, Grancini et al. [99] realized hysteresis-free mesoporous doubleperovskite solar cells by fine-tuning the material deposition 


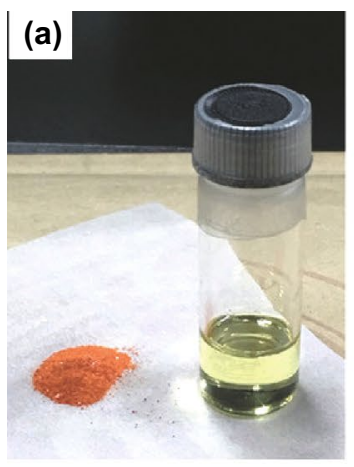

(b)
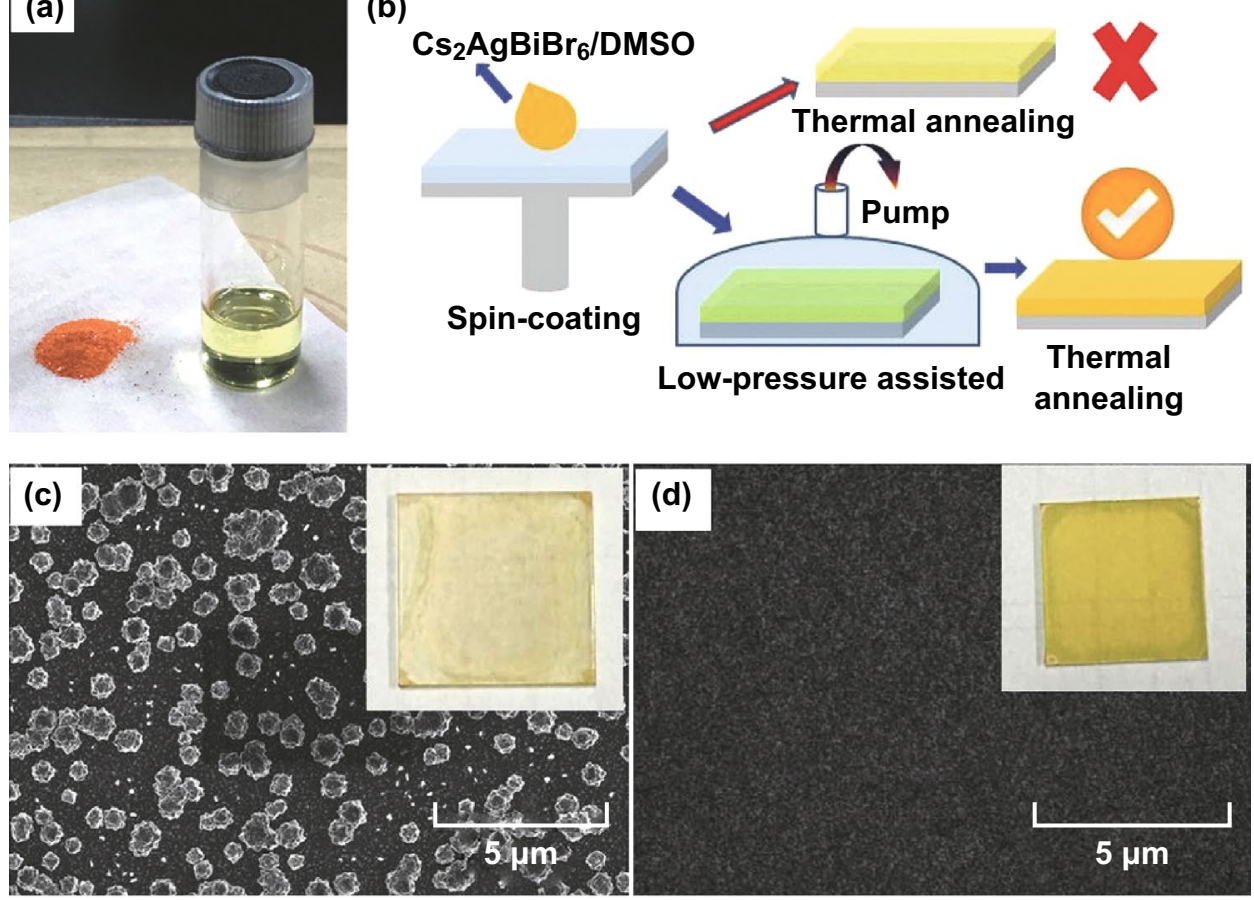

\section{(d)}

(e)

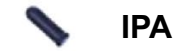

IPA
drop

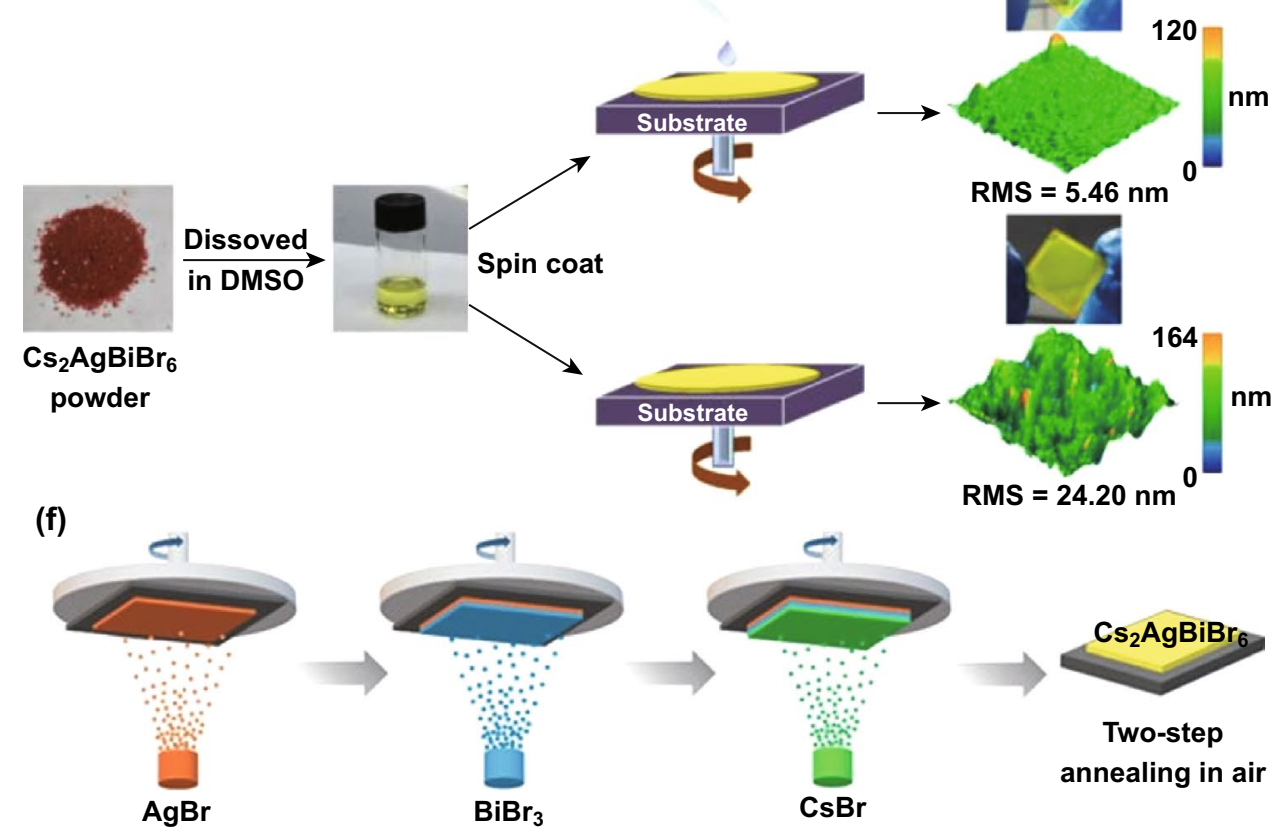

Fig. 7 a Image of $\mathrm{Cs}_{2} \mathrm{AgBiBr}_{6}$ powder (left) and solution in DMSO (right). b The film fabrication process diagram. c, d SEM images of film obtained by traditional thermally annealed and low-pressure-assisted process, respectively, inset: film photograph, size, $25 \times 25 \mathrm{~mm}^{2}$. Reproduced with permission from Ref. [97]. e Schematic illustration of the spin-coating process with and without anti-solvent dropping protocol; the morphology of the as-prepared film can be improved after IPA dropping. Reproduced with permission from Ref. [98]. f Scheme of sequential vapor deposition processing of $\mathrm{Cs}_{2} \mathrm{AgBiBr}_{6}$ double perovskite. Reproduced with permission from Ref. [100] 
parameters, enabling the growth of a highly uniform and compact $\mathrm{Cs}_{2} \mathrm{AgBiBr}_{6}$ film, and by engineering the device interfaces by screening different molecular and polymeric hole-transporting materials. Chlorobenzene was the antisolution in the film formation before the annealing step. Recently, Liu et al. [100] utilized a sequential vapor deposition method to fabricate $\mathrm{Cs}_{2} \mathrm{AgBiBr}_{6}$ films for solar cells, as shown in Fig. 7f. The two-step annealing process produces films with better quality in terms of crystallization and film uniformity. The solar cells with planar device structure show an optimized PCE of $1.37 \%$, which can be maintained at $90 \%$ after $240 \mathrm{~h}$ of storage under ambient condition. In addition, $\mathrm{Ma}$ et al. [64] incorporated their synthesized $\mathrm{Cs}_{2} \mathrm{NaBiI}_{6}$ into solar cells, which shows great stability and reproducibility.

It is greatly significative that the vacancy-ordered $\mathrm{A}_{2} \mathrm{M}(\mathrm{IV}) \mathrm{X}_{6}$ halide double perovskites have direct suitable bandgaps, which have been successfully applied in solar cells [74, 101-104]. In 2014, Kanatzidis et al. [74] first time introduced $\mathrm{Cs}_{2} \mathrm{SnI}_{6}$ as a hole-transporting material in dyesensitized solar cells. In 2016, Cao et al. [101] discovered that B- $\gamma-\mathrm{CsSnI}_{3}$ film can spontaneously convert to an airstable $\mathrm{Cs}_{2} \mathrm{SnI}_{6}$ film in air and at room temperature, which can be adopted as lead-free solar cell light absorber owing to its direct bandgap of $1.48 \mathrm{eV}$ and high absorption coefficient (over $105 \mathrm{~cm}^{-1}$ from $1.7 \mathrm{eV}$ ). A planar PSC using the $\mathrm{Cs}_{2} \mathrm{SnI}_{6}$ film as the light absorber achieved PCE nearly $1 \%$ in air. Later on, Cao et al. [102] synthesized $\mathrm{Cs}_{2} \mathrm{SnI}_{6}$ powder through a modified solution process and demonstrated its application as absorbing layer in mesoporous solar cell with a configuration of FTO/ZnO compact layer/ nanorods $/ \mathrm{Cs}_{2} \mathrm{SnI}_{6} / \mathrm{P}_{3} \mathrm{HT} / \mathrm{Ag}$. With careful control of $\mathrm{ZnO}$ nanorod length and pore size to ensure high loading of the $\mathrm{Cs}_{2} \mathrm{SnI}_{6}$ absorber, the PCE achieved was nearly $1 \%$. The bandgap tuning achieved by substitution of $\mathrm{Br}$ is anticipated to enhance the open-circuit voltage of $\mathrm{Cs}_{2} \mathrm{SnI}_{6}$-based solar cell. The compounds are $\mathrm{Cs}_{2} \mathrm{SnI}_{6-\mathrm{x}} \mathrm{Br}_{\mathrm{x}}$ for a range of $x$ that provide the desired bandgaps from 1.3 to $2.9 \mathrm{eV}$ with $x<3$ being suitable for solar cell design. The cells show a PCE of $2.1 \%$ for the case of the $x=2$ compound [103]. Recently, $\mathrm{Cs}_{2} \mathrm{TiBr}_{6}$ thin films were prepared through a facile low-temperature vapor-based method and incorporated into planar heterojunction PSCs [104]. The $\mathrm{Cs}_{2} \mathrm{TiBr}_{6}$ thin films exhibit favorable bandgap of $1.8 \mathrm{eV}$, long and balanced carrier diffusion lengths, suitable energy levels and superior intrinsic and environmental stability, which result in a stable solar cell with efficiency up to $3.3 \%$.

\section{Conclusion and Perspective}

Herein, we intend to summarize the most recent developments regarding halide double perovskite materials and the related applications. Due to distinguished stability and tunable properties, halide double perovskites have enormous potential leading to high-performance, stable and environmentally friendly optoelectronic devices for practical applications. Although significant progress has been achieved in halide double perovskites, there are still many challenges to be addressed.

Multitude of halide double perovskite materials to be existed is theoretically predicted, but a very limited number have been explored experimentally. In addition, synthesized strategies to those materials remain limited, which are mainly divided into solid-state and wet-chemical routes. The solid-state route is processed to heat anhydrous haloids as melt crystallization. Wet-chemical route includes hot injection, antisolvent recrystallization, hydrothermal methods, etc. The single crystals are classically obtained by the hydrothermal method through controlling the cooling rate from hot solution. Because a few iodine-based double perovskite materials are not easily obtained by direct combination of reactants, anion exchange and induced crystallization have been taken [51, 87]. Accordingly, we propose two aspects to make efforts: borrowing the present routes to explore the theoretical predictions and discovering viable routes to more halide double perovskite materials.

The present halide double perovskite materials exhibit excellent stability in moisture, heat and light, unlike the fashionable $\mathrm{Pb}$-based perovskite materials. For instance, $(\mathrm{MA})_{2} \mathrm{AgSbI}_{6}$ powder is relatively unaltered after being exposed to air for 370 days and the thermal stability can be up to $260{ }^{\circ} \mathrm{C}$ [84]. As a general rule, all-inorganic halide perovskites possess better stability [105-107]. $\mathrm{Cs}_{2} \mathrm{AgBiBr}_{6}$ single crystal is stable up to $430{ }^{\circ} \mathrm{C}$, and differential thermal analysis indicates no phase transitions within this temperature range [42]. $\mathrm{Cs}_{2} \mathrm{NaBiI}_{6}$ exhibits superior stability against the moisture and the oxygen in the ambient air, which can be washed with water [53]. However, there is lack of proven stability under complicated environmental conditions or with long term over 10 years. In addition, the underlying cause of stability under different conditions remains covered. Hence, more attempts need to place emphasis on enhancing 
long-term and complicated environmental stability, as well as discovering the stability mechanisms.

Hitherto, extremely few all-inorganic and no hybrid halide double perovskite materials have been developed for optoelectronic applications. More halide double perovskite materials are desirable to be developed and widely applied. Moreover, the optoelectronic devices based on single-crystal halide double perovskite materials enjoy pleasurable performance, comparable to that of $\mathrm{Pb}$-based perovskite analogs, such as $\mathrm{Cs}_{2} \mathrm{AgBiBr}_{6}$ single-crystal $\mathrm{X}$-ray detectors [54]. However, the device performance of halide double perovskite films is still lower than that of the $\mathrm{Pb}$-based perovskite analogs. The underlying causes can be ascribed to the underdeveloped electronic structures, material properties, film qualities of halide double perovskite materials and device architectures. It is difficult to develop a synthetic route to obtain uniform thin films of the correct phase and composition. Typically, $\mathrm{Cs}_{2} \mathrm{AgBiBr}_{6}$ [96], $\mathrm{Cs}_{2} \mathrm{SnI}_{6-\mathrm{x}} \mathrm{Br}_{\mathrm{x}}$ [103] and $\mathrm{Cs}_{2} \mathrm{TiBr}_{6}$ [104] absorbers in PSCs have achieved optimized efficiency of 2.4, 2.1 and $3.3 \%$, respectively, far below that of the $\mathrm{Pb}$-based perovskite analogs. To enhance $\mathrm{Cs}_{2} \mathrm{AgBiBr}_{6}$-film quality, antisolvent dropping and low-pressure-assisted solution methods have been adopted [97, 98]. Interface engineering of device architectures was taken to achieve hysteresis-free $\mathrm{Cs}_{2} \mathrm{AgBiBr}_{6}$-based PSCs [99]. However, the performance is still unsatisfactory because $\mathrm{Cs}_{2} \mathrm{AgBiBr}_{6}$ has a relatively large indirect bandgap. Various strategies can be attempted to engineer the bandgap and modify the device structures to improve the device performance, such as chemical doping and alloying approaches. Meanwhile, chemical doping and alloying approaches are expected to bring original effects for applications. As an example, Bi-doped $\mathrm{Cs}_{2} \mathrm{SnCl}_{6}$ can be applied as blue emissive phosphors, where $\mathrm{Bi}^{3+}$ is the luminescent dopant [77].

In summary, we are very much optimistic that the current astonishing achievements will encourage more researchers to overcome the above challenges in the future.

Acknowledgements This work was financially supported by the Ministry of Education of China (IRT1148), the National Natural Science Foundation of China (U1732126, 11804166, 51602161, 51372119 ), the National Synergetic Innovation Center for Advanced Materials (SICAM), the China Postdoctoral Science Foundation (2018M630587), the Priority Academic Program Development of Jiangsu Higher Education Institutions (YX03001) and the Natural Science Foundation of NJUPT (NY217091).
Open Access This article is distributed under the terms of the Creative Commons Attribution 4.0 International License (http:// creativecommons.org/licenses/by/4.0/), which permits unrestricted use, distribution, and reproduction in any medium, provided you give appropriate credit to the original author(s) and the source, provide a link to the Creative Commons license, and indicate if changes were made.

\section{References}

1. A. Kojima, K. Teshima, Y. Shirai, T. Miyasaka, Organometal halide perovskites as visible-light sensitizers for photovoltaic cells. J. Am. Chem. Soc. 131(17), 6050-6051 (2009). https:// doi.org/10.1021/ja809598r

2. H.S. Kim, C.R. Lee, J.H. Im, K.B. Lee, T. Moehl et al., Lead iodide perovskite sensitized all-solid-state submicron thin film mesoscopic solar cell with efficiency exceeding $9 \%$. Sci. Rep. 2, 6022-6025 (2012). https://doi.org/10.1038/srep00591

3. H. Zhou, Q. Chen, G. Li, S. Luo, T.B. Song et al., Interface engineering of highly efficient perovskite solar cells. Science 345(6196), 542-546 (2014). https://doi.org/10.1126/scien ce. 1254050

4. N.J. Jeon, J.H. Noh, W.S. Yang, Y.C. Kim, S. Ryu, J. Seo, S.I. Seok, Compositional engineering of perovskite materials for high-performance solar cells. Nature 517, 476-480 (2015). https://doi.org/10.1038/nature14133

5. D. Luo, W. Yang, Z. Wang, A. Sadhanala, Q. Hu et al., Enhanced photovoltage for inverted planar heterojunction perovskite solar cells. Science 360(6396), 1442 (2018). https ://doi.org/10.1126/science.aap9282

6. National Renewable Energy Laboratory (NREL) (2018). https ://www.nrel.gov/pv/assets/pdfs/pv-efficiencies-chart.20181 214.pdf

7. M.M. Lee, J. Teuscher, T. Miyasaka, T.N. Murakumi, H.J. Snaith, Efficient hybrid solar cells based on meso-superstructured organometal halide perovskites. Science 338(6107), 643-647 (2012). https://doi.org/10.1126/science.1228604

8. S.D. Stranks, G.E. Eperon, G. Grancini, C. Menelaou, M.J.P. Alcocer, T. Leijtens, L.M. Hertz, A. Petrozza, H.J. Snaith, Electron-hole diffusion lengths exceeding 1 micrometer in an organometal trihalide perovskite absorber. Science 342(6156), 341-344 (2013). https://doi.org/10.1126/scien ce. 1243982

9. G.C. Xing, N. Mathews, S.Y. Sun, S.S. Lim, Y.M. Lam, M. Gratzel, S. Mhaisalkar, T.C. Sum, Long-range balanced electron-and hole-transport lengths in organic-inorganic $\mathrm{CH}_{3} \mathrm{NH}_{3} \mathrm{PbI}_{3}$. Science 342(6156), 344-347 (2013). https:// doi.org/10.1126/science.1243167

10. W.S. Yang, B.W. Park, E.H. Jung, N.J. Jeon, Y.C. Kim et al., Iodide management in formamidinium-lead-halide-based perovskite layers for efficient solar cells. Science 356(6345), 1376-1379 (2017). https://doi.org/10.1126/science.aan2301

11. S.D. Stranks, H.J. Snaith, Metal-halide perovskites for photovoltaic and light-emitting devices. Nat. Nanotech. 10(5), 391-402 (2015). https://doi.org/10.1038/nnano.2015.90 
12. H. Cho, S.H. Jeong, M.H. Park, Y.H. Kim, C. Wolf, C.L. Lee et al., Overcoming the electroluminescence efficiency limitations of perovskite light-emitting diodes. Science 350(6265), 1222-1225 (2015). https://doi.org/10.1126/science.aad1818

13. H. Zhu, Y. Fu, F. Meng, X. Wu, Z. Gong et al., Lead halide perovskite nanowire lasers with low lasing thresholds and high quality factors. Nat. Mater. 14(6), 636-642 (2015). https ://doi.org/10.1038/nmat4271

14. F. Zhang, B. Yang, K. Zheng, S. Yang, Y. Li, W. Deng, R. He, Formamidinium lead bromide $\left(\mathrm{FAPbBr}_{3}\right)$ perovskite microcrystals for sensitive and fast photodetectors. NanoMicro Lett. 10(3), 43 (2018). https://doi.org/10.1007/s4082 0-018-0196-2

15. L. Chu, R. Hu, W. Liu, Y. Ma, R. Zhang, J. Yang, X. Li, Screen printing large-area organometal halide perovskite thin films for efficient photodetectors. Mater. Res. Bull. 98, 322 (2018). https://doi.org/10.1016/j.materresbull.2017.10.039

16. Q. Chen, J. Wu, X. Ou, B. Huang, J. Almutlaq et al., All-inorganic perovskite nanocrystal scintillators. Nature 561(7721), 88 (2018). https://doi.org/10.1038/s41586-018-0451-1

17. H. Luo, X. Lin, X. Hou, L. Pan, S. Huang, X. Chen, Efficient and air-stable planar perovskite solar cells formed on grapheneoxide-modified PEDOT:PSS hole transport layer. Nano-Micro Lett. 9(4), 39 (2017). https://doi.org/10.1007/s4082

18. Y. Yang, J. You, Make perovskite solar cells stable. Nature 544(7649), 155 (2017). https://doi.org/10.1038/544155a

19. M. Saliba, T. Matsui, K. Domanski, J.Y. Seo, A. Ummadisingu et al., Incorporation of rubidium cations into perovskite solar cells improves photovoltaic performance. Science 354(6309), 5557 (2016). https://doi.org/10.1126/scien ce.aah5557

20. J.M. Ball, A. Petrozza, Defects in perovskite-halides and their effects in solar cells. Nat. Energy 1(11), 16149 (2016). https ://doi.org/10.1038/nenergy.2016.149

21. J. Cheng, H. Zhang, S. Zhang, D. Ouyang, Z. Huang, M.K. Nazeeruddin, J. Hou, W.C. Choy, Highly efficient planar perovskite solar cells achieved by simultaneous defect engineering and formation kinetic control. J. Mater. Chem. A 6(46), 23865 (2018). https://doi.org/10.1039/C8TA08819E

22. J.C. Hebig, I. Kühn, J. Flohre, T. Kirchartz, Optoelectronic properties of $\left(\mathrm{CH}_{3} \mathrm{NH}_{3}\right)_{3} \mathrm{Sb}_{2} \mathrm{I}_{9}$ thin films for photovoltaic applications. ACS Energy Lett. 1(1), 309-314 (2016). https ://doi.org/10.1021/acsenergylett.6b00170

23. T. Singh, A. Kulkarni, M. Ikegami, T. Miyasaka, Effect of electron transporting layer on bismuth-based lead-free perovskite $\left(\mathrm{CH}_{3} \mathrm{NH}_{3}\right)_{3} \mathrm{Bi}_{2} \mathrm{I}_{9}$ for photovoltaic applications. ACS Appl. Mater. Interfaces. 8(23), 14542-14547 (2016). https:// doi.org/10.1021/acsami.6b02843

24. J. You, L. Meng, T.B. Song, T.F. Guo, Y.M. Yang et al., Improved air stability of perovskite solar cells via solutionprocessed metal oxide transport layers. Nat. Nanotech. 11(1), 75-81 (2016). https://doi.org/10.1038/nnano.2015.230

25. W. Liao, D. Zhao, Y. Yu, C.R. Grice, C. Wang et al., Leadfree inverted planar formamidinium tin triiodide perovskite solar cells achieving power conversion efficiencies up to
6.22\%. Adv. Mater. 28(42), 9333-9340 (2016). https://doi. org/10.1002/adma.201602992

26. H. Tsai, W. Nie, J.C. Blancon, C.C. Stoumpos, R. Asadpour et al., High-efficiency two-dimensional ruddlesden-popper perovskite solar cells. Nature 536(7616), 312-316 (2016). https://doi.org/10.1038/nature18306

27. F. Matteocci, L. Cinà, E. Lamanna, S. Cacovich, G. Divitini, P.A. Midgley, C. Ducati, A.D. Carlo, Encapsulation for longterm stability enhancement of perovskite solar cells. Nano Energy 30, 162-172 (2016). https://doi.org/10.1016/j.nanoe n.2016.09.041

28. G. Flora, D. Gupta, A. Tiwari, Toxicity of lead: a review with recent updates. Interdiscip. Toxicol. 5(2), 47-58 (2012). https ://doi.org/10.2478/v10102-012-0009-2

29. L. Liang, P. Gao, Lead-free hybrid perovskite absorbers for viable application: can we eat the cake and have it too. Adv. Sci. 5(2), 1700331 (2018). https://doi.org/10.1002/ advs.201700331

30. F. Hao, C.C. Stoumpos, R.P.H. Chang, M.G. Kanatzidis, Anomalous band gap behavior in mixed $\mathrm{Sn}$ and $\mathrm{Pb}$ perovskites enables broadening of absorption spectrum in solar cells. J. Am. Chem. Soc. 136(22), 8094-8099 (2014). https ://doi.org/10.1021/ja5033259

31. T. Krishnamoorthy, H. Ding, C. Yan, W.L. Leong, T. Baikie et al., Lead-free germanium iodide perovskite materials for photovoltaic applications. J. Mater. Chem. A 3(47), 23829_ 23832 (2015). https://doi.org/10.1039/C5TA05741H

32. H. Wang, H. Zhang, C.C. Chueh, T. Zhao, C. Mao, W. Chen, A.K.Y. Jenac, Enhanced crystallization and performance of formamidinium lead triiodide perovskite solar cells through $\mathrm{PbI}_{2}-\mathrm{SrCl}_{2}$ modulation. Mater. Today Energy 7, 239 (2018). https://doi.org/10.1016/j.mtener.2017.10.002

33. M.T. Klug, A. Osherov, A.A. Haghighirad, S.D. Stranks, P.R. Brown et al., Tailoring metal halide perovskites through metal substitution: influence on photovoltaic and material properties. Energy Environ. Sci. 10(1), 236 (2017). https:// doi.org/10.1039/C6EE03201J

34. J. Jin, H. Li, C. Chen, B. Zhang, L. Xu, B. Dong, H. Song, Q. Dai, Enhanced performance of perovskite solar cells with zinc chloride additives. ACS Appl. Mater. Interfaces. 9(49), 42875-42882 (2017). https://doi.org/10.1021/acsami.7b153 10

35. Q. Chen, L. Chen, F.Y. Ye, T. Zhao, F. Tang et al., Ag-incorporated organic-inorganic perovskite films and planar heterojunction solar cells. Nano Lett. 17(5), 3231-3237 (2017). https://doi.org/10.1021/acs.nanolett.7b00847

36. J. Zhang, M. Shang, P. Wang, X. Huang, J. Xu, Z. Hu, Y. Zhu, L. Han, n-Type doping and energy states tuning in $\mathrm{CH}_{3} \mathrm{NH}_{3} \mathrm{~Pb}_{1-\mathrm{x}} \mathrm{Sb}_{2 \times / 3} \mathrm{I}_{3}$ perovskite solar cells. ACS Energy Lett. 1(3), 535-541 (2016). https://doi.org/10.1021/acsen ergylett.6b00241

37. Y. Hu, T. Qiu, F. Bai, X. Miao, S. Zhang, Enhancing moisture-tolerance and photovoltaic performances of $\mathrm{FAPbI}_{3}$ by bismuth incorporation. J. Mater. Chem. A 5(48), 2525825265 (2017). https://doi.org/10.1039/C7TA08824H 
38. F. Wei, Z. Deng, S. Sun, F. Xie, G. Kieslich, D.M. Evans, M.A. Carpenter, P.D. Bristowe, A.K. Cheetham, The synthesis, structure and electronic properties of a lead-free hybrid inorganic-organic double perovskite $(\mathrm{MA})_{2} \mathrm{KBiCl}_{6}$ (MA = methylammonium). Mater. Horiz. 3(4), 328-332 (2016). https://doi.org/10.1039/C6MH00053C

39. P.D. Matthews, D.J. Lewis, P. O'Brien, Updating the road map to metal-halide perovskites for photovoltaics. J. Mater. Chem. A 5(33), 17135-17150 (2017). https://doi. org/10.1039/C7TA04544A

40. F. Giustino, H.J. Snaith, Toward lead-free perovskite solar cells. ACS Energy Lett. 1(6), 1233-1240 (2016). https://doi. org/10.1021/acsenergylett.6b00499

41. K.W. Bagnall, J.B. Laidler, M.A.A. Stewart, Americium chloro-complexes. J. Chem. Soc. A 0, 133-136 (1968). https ://doi.org/10.1039/J19680000133

42. L.R. Morss, J. Fuger, Preparation and crystal structures of dicesium berkelium hexachloride and dicesium sodium berkelium hexachloride. Inorg. Chem. 8(7), 1433-1439 (1969). https://doi.org/10.1021/ic50077a013

43. L.R. Morss, M. Siegal, L. Stenger, N. Edelstein, Preparation of cubic chloro complex compounds of trivalent metals: $\mathrm{Cs}_{2} \mathrm{NaMCl}_{6}$. Inorg. Chem. 9(7), 1771-1775 (1970). https:// doi.org/10.1021/ic50089a034

44. L.R. Morrs, W.R. Robinson, Crystal structure of $\mathrm{Cs}_{2} \mathrm{NaBiCl}_{6}$. Acta Crystallogr. B 28(2), 653-654 (1972). https://doi. org/10.1107/S0567740872002948

45. F. Prokert, K.S. Aleksandrov, Neutron scattering studies on phase transition and phonon dispersion in $\mathrm{Cs}_{2} \mathrm{NaBiCl}_{6}$. Phys. Status Solidi B 124(2), 503 (1984). https://doi.org/10.1002/ pssb. 2221240208

46. W.M.A. Smit, G.J. Dirksen, D.J. Stufkens, Infrared and Raman spectra of the elpasolites $\mathrm{Cs}_{2} \mathrm{NaSbCl}_{6}$ and $\mathrm{Cs}_{2} \mathrm{NaBiCl}_{6}$ : evidence for a pseudo Jahn-Teller distorted ground state. J. Phys. Chem. Solids 51(2), 189-196 (1990). https://doi.org/10.1016/0022-3697(90)90092-T

47. I.N. Flerov, M.V. Gorev, K.S. Aleksandrov, A. Tressaud, J. Grannec, M. Couzi, Phase transitions in elpasolites (ordered perovskites). Mater. Sci. Eng. 24(3), 81-151 (1998). https:// doi.org/10.1016/S0927-796X(98)00015-1

48. E.T. McClure, M.R. Ball, W. Windl, P.M. Woodward, $\mathrm{Cs}_{2} \mathrm{AgBiX}_{6}(\mathrm{X}=\mathrm{Br}, \mathrm{Cl})$ : new visible light absorbing, leadfree halide perovskite semiconductors. Chem. Mater. 28(5), 1348-1354 (2016). https://doi.org/10.1021/acs.chemm ater.5b04231

49. G. Volonakis, M.R. Filip, A.A. Haghighirad, N. Sakai, B. Wenger, H.J. Snaith, F. Giustino, Lead-free halide double perovskites via heterovalent substitution of noble metals. J. Phys. Chem. Lett. 7(7), 1254-1259 (2016). https://doi. org/10.1021/acs.jpclett.6b00376

50. Y. Bekenstein, J.C. Dahl, J. Huang, W.T. Osowiecki, J.K. Swabeck, E.M. Chan, P. Yang, A.P. Alivisatos, The making and breaking of lead-free double perovskite nanocrystals of cesium silver-bismuth halide compositions. Nano Lett. 18(6), 3502 (2018). https://doi.org/10.1021/acs.nanol ett. $8 \mathrm{~b} 00560$
51. S.E. Creutz, E.N. Crites, M.C. De Siena, D.R. Gamelin, Colloidal nanocrystals of lead-free double-perovskite (elpasolite) semiconductors: synthesis and anion exchange to access new materials. Nano Lett. 18(2), 1118 (2018). https://doi. org/10.1021/acs.nanolett.7b04659

52. A.H. Slavney, T. Hu, A.M. Lindenberg, H.I. Karunadasa, A bismuth-halide double perovskite with long carrier recombination lifetime for photovoltaic application. J. Am. Chem. Soc. 138(7), 2138-2141 (2016). https://doi.org/10.1021/ jacs.5b13294

53. Y. Bi, E.M. Hutter, Y. Fang, Q. Dong, J. Huang, T.J. Savenije, Charge carrier lifetimes exceeding $15 \mu \mathrm{s}$ in methylammonium lead iodide single crystals. J. Phys. Chem. Lett. 7(5), 923-928 (2016). https://doi.org/10.1021/acs.jpclett.6b00269

54. W. Pan, H. Wu, J. Luo, Z. Deng, C. Ge et al., Cs2AgBiBr 6 single-crystal X-ray detectors with a low detection limit. Nat. Photonics 11(11), 726-732 (2017). https://doi.org/10.1038/ s41566-017-0012-4

55. R.L.Z. Hoye, L. Eyre, F. Wei, F. Brivio, A. Sadhanala et al., Fundamental carrier lifetime exceeding $1 \mu$ s in $\mathrm{Cs} 2 \mathrm{AgBiBr}$ 6 double perovskite. Adv. Mater. Interfaces 5(15), 1800464 (2018). https://doi.org/10.1002/admi.201800464

56. L. Zhou, Y.F. Xu, B.X. Chen, D.B. Kuang, C.Y. Su, Synthesis and photocatalytic application of stable lead-free $\mathrm{Cs} 2 \mathrm{AgBiBr}$ 6 perovskite nanocrystals. Small 14(11), 1703762 (2018). https://doi.org/10.1002/smll.201703762

57. A.H. Slavney, L. Leppert, D. Bartesaghi, A. Gold-Parker, M.F. Toney, T.J. Savenije, J.B. Neaton, H.I. Karunadasa, Defect-induced band-edge reconstruction of a bismuth-halide double perovskite for visible-light absorption. J. Am. Chem. Soc. 139(14), 5015-5018 (2017). https://doi.org/10.1021/ jacs.7b01629

58. K.Z. Du, W. Meng, X. Wang, Y. Yan, D.B. Mitzi, Bandgap engineering of lead-free double perovskite Cs2Ag$\mathrm{BiBr} 6$ through trivalent metal alloying. Angew. Chem. Int. Ed. 56(28), 8158-8274 (2017). https://doi.org/10.1002/ anie. 201703970

59. T.T. Tran, J.R. Panella, J.R. Chamorro, J.R. Morey, T.M. McQueen, Designing indirect-direct bandgap transitions in double perovskites. Mater. Horiz. 4(4), 688-693 (2017). https ://doi.org/10.1039/C7MH00239D

60. G. Volonakis, A.A. Haghighirad, R.L. Milot, W.H. Sio, M.R. Filip et al., $\mathrm{Cs}_{2} \mathrm{InAgCl}_{6}$ : a new lead-free halide double perovskite with direct band gap. J. Phys. Chem. Lett. 8(4), 772-778 (2017). https://doi.org/10.1021/acs.jpclett.6b02682

61. J. Luo, S. Li, H. Wu, Y. Zhou, Y. Li et al., $\mathrm{Cs}_{2} \mathrm{AgInCl}_{6}$ double perovskite single crystals: parity forbidden transitions and their application for sensitive and fast UV photodetectors. ACS Photonics 5(2), 398-405 (2017). https://doi. org/10.1021/acsphotonics.7b00837

62. N. Nandha, A. Nag, Synthesis and luminescence of Mn-doped $\mathrm{Cs}_{2} \mathrm{AgInCl}_{6}$ double perovskites. Chem. Comm. 54(41), 52055208 (2018). https://doi.org/10.1039/C8CC01982G

63. K. Tanaka, T. Takahashi, T. Ban, T. Kondo, K. Uchida, N. Miura, Comparative study on the excitons in lead-halidebased perovskite-type crystals $\mathrm{CH}_{3} \mathrm{NH}_{3} \mathrm{PbBr}_{3} \mathrm{CH} 3 \mathrm{NH} 3 \mathrm{PbI} 3$. 
Solid State Commun. 127(9-10), 619-623 (2003). https://doi. org/10.1016/S0038-1098(03)00566-0

64. C. Zhang, L. Gao, S. Teo, Z. Guo, Z. Xu, S. Zhao, T. Ma, Design of a novel and highly stable lead-free $\mathrm{Cs}_{2} \mathrm{NaBiI}_{6}$ double perovskite for photovoltaic application. Sustainable Energy Fuels 2(11), 2419 (2018). https://doi.org/10.1039/ C8SE00154E

65. X.G. Zhao, J.H. Yang, Y. Fu, D. Yang, Q. Xu, L. Yu, S.H. Wei, L. Zhang, Design of lead-free inorganic halide perovskites for solar cells via cation-transmutation. J. Am. Chem. Soc. 139(7), 2630-2638 (2017). https://doi.org/10.1021/ jacs.6b09645

66. T. Li, X. Zhao, D. Yang, M.H. Du, L. Zhang, Intrinsic defect properties in halide double perovskites for optoelectronic applications. Phys. Rev. Appl. 10(4), 41001 (2018). https:// doi.org/10.1103/PhysRevApplied.10.041001

67. X.G. Zhao, D. Yang, J.C. Ren, Y. Sun, Z. Xiao, L. Zhang, Rational design of halide double perovskites for optoelectronic applications. Joule 2(9), 1662 (2018). https://doi. org/10.1016/j.joule.2018.06.017

68. Q. Xu, D. Yang, J. Lv, Y.Y. Sun, L. Zhang, Perovskite solar absorbers: materials by design. Small Methods 2(5), 1700316 (2018). https://doi.org/10.1002/smtd.201700316

69. X.G. Zhao, D. Yang, Y. Sun, T. Li, L. Zhang, L. Yu, A. Zunger, Cu-In halide perovskite solar absorbers. J. Am. Chem. Soc. 139(19), 6718-6725 (2017). https://doi. org/10.1021/jacs.7b02120

70. Z.W. Xiao, K.Z. Du, W.W. Meng, J.B. Wang, D.B. Mitzi, Y.F. Yan, Intrinsic instability of $\mathrm{Cs}_{2} \mathrm{In}(\mathrm{I}) \mathrm{M}(\mathrm{III}) \mathrm{X}_{6}(\mathrm{M}=\mathrm{Bi}$, $\mathrm{Sb} ; \mathrm{X}=$ Halogen) double perovskites: a combined density functional theory and experimental study. J. Am. Chem. Soc. 139(17), 6054-6057 (2017). https://doi.org/10.1021/ jacs.7b02227

71. M.G. Brik, I.V. Kityk, Modeling of lattice constant and their relations with ionic radii and electronegativity of constituting ions of $\mathrm{A}_{2} \mathrm{XY}_{6}$ cubic crystals $(\mathrm{A}=\mathrm{K}, \mathrm{Cs}, \mathrm{Rb}, \mathrm{Tl}$; $\mathrm{X}=$ tetravalent cation, $\mathrm{Y}=\mathrm{F}, \mathrm{Cl}, \mathrm{Br}, \mathrm{I})$. J. Phys. Chem. Solids 72(11), 1256-1260 (2011). https://doi.org/10.1016/j. jpcs.2011.07.016

72. A.E. Maughan, A.M. Ganose, M.M. Bordelon, E.M. Miller, D.O. Scanlon, J.R. Neilson, Defect tolerance to intolerance in the vacancy-ordered double perovskite semiconductors $\mathrm{Cs}_{2} \mathrm{SnI}_{6}$ and $\mathrm{Cs}_{2} \mathrm{TeI}_{6}$. J. Am. Chem. Soc. 138(27), 8453-8464 (2016). https://doi.org/10.1021/jacs.6b03207

73. A.E. Maughan, A.M. Ganose, A.M. Candia, J.T. Granger, D.O. Scanlon, J.R. Neilson, Anharmonicity and octahedral tilting in hybrid vacancy-ordered double perovskites. Chem. Mater. 30(2), 472-482 (2018). https://doi.org/10.1021/acs. chemmater.7b04516

74. B. Lee, C.C. Stoumpos, N. Zhou, F. Hao, C. Malliakas, C.Y. Yeh, T.J. Marks, M.G. Kanatzidis, R.P.H. Chang, Air-stable molecular semiconducting iodosalts for solar cell applications: $\mathrm{Cs}_{2} \mathrm{SnI}_{6}$ as a hole conductor. J. Am. Chem. Soc. 136(43), 15379-15385 (2014). https://doi.org/10.1021/ja508 $464 \mathrm{w}$
75. S. Ghosh, S. Paul, S.K. De, Control synthesis of air-stable morphology tunable $\mathrm{Pb}$-free $\mathrm{Cs}_{2} \mathrm{SnI}_{6}$ perovskite nanoparticles and their photodetection properties. Part. Part. Syst. Char. 35(9), 1800199 (2018). https://doi.org/10.1002/ppsc.20180 0199

76. A. Wang, X. Yan, M. Zhang, S. Sun, M. Yang, W. Shen, X. Pan, P. Wang, Z. Deng, Controlled synthesis of lead-free and stable perovskite derivative $\mathrm{Cs}_{2} \mathrm{SnI}_{6}$ nanocrystals via a facile hot-injection process. Chem. Mater. 28(22), 8132-8140 (2016). https://doi.org/10.1021/acs.chemmater.6b01329

77. Z. Tan, J. Li, C. Zhang, Z. Li, Q. Hu et al., Highly efficient blue-emitting $\mathrm{Bi}$-doped $\mathrm{Cs} 2 \mathrm{SnCl} 6$ perovskite variant: photoluminescence induced by impurity doping. Adv. Funct. Mater. 28(29), 1801131 (2018). https://doi.org/10.1002/ adfm.201801131

78. N. Sakai, A.A. Haghighirad, M.R. Filip, P.K. Nayak, S. Nayak et al., Solution-processed cesium hexabromopalladate(IV), Cs2PdBr 6, for optoelectronic applications. J. Am. Chem. Soc. 139(17), 6030-6033 (2017). https://doi.org/10.1021/ jacs.6b13258

79. L. Zhou, J.F. Liao, Z.G. Huang, X.D. Wang, Y.F. Xu, H.Y. Chen, D.B. Kuang, C.Y. Su, All-inorganic lead-free $\mathrm{Cs}_{2} \mathrm{PdX}_{6}$ $(\mathrm{X}=\mathrm{Br}, \mathrm{I})$ perovskite nanocrystals with single unit cell thickness and high stability. ACS Energy Lett. 3(10), 2613-2619 (2018). https://doi.org/10.1021/acsenergylett.8b01770

80. K.F. Guenther, The preparation of some alkali hexabromotitanates (IV). Inorg. Chem. 3(12), 1788-1789 (1964). https:// doi.org/10.1021/ic50022a033

81. M.G. Ju, M. Chen, Y. Zhou, H.F. Garces, J. Dai et al., Earthabundant nontoxic titanium (IV)-based vacancy-ordered double perovskite halides with tunable 1.0 to $1.8 \mathrm{eV}$ bandgaps for photovoltaic applications. ACS Energy Lett. 3(2), 297-304 (2018). https://doi.org/10.1021/acsenergylett.7b01167

82. Z. Deng, F. Wei, S. Sun, G. Kieslich, A.K. Cheetham, P.D. Bristowe, Exploring the properties of lead-free hybrid double perovskites using a combined computational-experimental approach. J. Mater. Chem. A 4(31), 12025-12029 (2016). https://doi.org/10.1039/C6TA05817E

83. F.X. Wei, Z.Y. Deng, S.J. Sun, F.H. Zhang, D.M. Evans et al., Synthesis and properties of a lead-free hybrid double perovskite: (CH3NH3)2AgBiBr 6. Chem. Mater. 29(3), 1089-1094 (2017). https://doi.org/10.1021/acs.chemmater.6b03944

84. Y.J. Li, T. Wu, L. Sun, R.X. Yang, L. Jiang et al., Leadfree and stable antimony-silver-halide double perovskite $\left(\mathrm{CH}_{3} \mathrm{NH}_{3}\right)_{2} \mathrm{AgSbI}_{6}$. RSC Adv. 7(56), 3517-35180 (2017). https://doi.org/10.1039/C7RA06130G

85. P. Cheng, T. Wu, Y. Li, L. Jiang, W. Deng, K. Han, Combining theory and experiment in the design of a lead-free $\left(\left(\mathrm{CH}_{3} \mathrm{NH}_{3}\right)_{2} \mathrm{AgBiI}{ }_{6}\right)$ double perovskite. New J. Chem. 41, 9598-9601 (2017). https://doi.org/10.1039/C7NJ02365K

86. Z. Deng, F. Wei, F. Brivio, Y. Wu, S. Sun, P.D. Bristowe, A.K. Cheetham, Synthesis and characterization of the rareearth hybrid double perovskites: $\left(\mathrm{CH}_{3} \mathrm{NH}_{3}\right)_{2} \mathrm{KGdCl}_{6}$ and $\left(\mathrm{CH}_{3} \mathrm{NH}_{3}\right)_{2} \mathrm{KYCl}_{6}$. J. Phys. Chem. Lett. 8(20), 5015-5020 (2017). https://doi.org/10.1021/acs.jpclett.7b02322 
87. T.T. Tran, M.A. Quintero, K.E. Arpino, Z.A. Kelly, J.R. Panella, X. Wang, T.M. McQueen, Chemically controlled crystal growth of (CH3NH3)2AgInBr 6. CrystEngComm 20, 59295934 (2018). https://doi.org/10.1039/C8CE00702K

88. F. Funabiki, Y. Toda, H. Hosono, Optical and electrical properties of perovskite variant $\left(\mathrm{CH}_{3} \mathrm{NH}_{3}\right)_{2} \mathrm{SnI}_{6}$. J. Phys. Chem. C 122(20), 10749 (2018). https://doi.org/10.1021/ acs.jpcc.8b01820

89. W. Meng, X. Wang, Z. Xiao, J. Wang, D.B. Mitzi, Y.J. Yan, Parity-forbidden transitions and their impact on the optical absorption properties of lead-free metal halide perovskites and double perovskites. J. Phys. Chem. Lett. 8(13), 29993007 (2017). https://doi.org/10.1021/acs.jpclett.7b01042

90. L.Z. Lei, Z.F. Shi, Y. Li, Z.Z. Ma, F. Zhang et al., Highefficiency and air-stable photodetectors based on lead-free double perovskite $\mathrm{Cs} 2 \mathrm{AgBiBr} 6$ thin films. J. Mater. Chem. C 6(30), 7982-7988 (2018). https://doi.org/10.1039/C8TC0 $2305 \mathrm{~K}$

91. C. Wu, B. Du, W. Luo, Y. Liu, T. Li et al., Highly efficient and stable self-powered ultraviolet and deep-blue photodetector based on $\mathrm{Cs} 2 \mathrm{AgBiBr} 6 / \mathrm{SnO} 2$ heterojunction. Adv. Optical Mater. (2018). https://doi.org/10.1002/adom.201800811

92. H. Li, X. Shan, J.N. Neu, T. Geske, M. Davis, P. Mao, K. Xiao, T. Siegrist, Z. Yu, Lead-free halide double perovskitepolymer composites for flexible X-ray imaging. J. Mater. Chem. C 6, 11961-11967 (2018). https://doi.org/10.1039/ C8TC01564C

93. Q. Hu, Z. Deng, M. Hu, A. Zhao, Y. Zhang, Z. Tan, G. Niu, $\mathrm{H}$. Wu, J. Tang, X-ray scintillation in lead-free double perovskite crystals. Sci. China Chem. 61, 1 (2018). https://doi. org/10.1007/s11426-018-9308-2

94. J. Luo, X. Wang, S. Li, J. Liu, Y. Guo et al., Efficient and stable emission of warm-white light from lead-free halide double perovskites. Nature 563, 541-545 (2018). https://doi. org/10.1038/s41586-018-0691-0

95. F. Moser, S. Lyu, Luminescence in pure and I-doped AgBr crystals. J. Lumin. 3(6), 447-458 (1971). https://doi. org/10.1016/0022-2313(71)90025-1

96. E. Greul, M.L. Petrus, A. Binek, P. Docampo, T. Bein, Highly stable, phase pure $\mathrm{Cs}_{2} \mathrm{AgBiBr}_{6}$ double perovskite thin films for optoelectronic applications. J. Mater. Chem. A 5(37), 19972-19981 (2017). https://doi.org/10.1039/C7TA06816F

97. C. Wu, Q. Zhang, Y. Liu, W. Luo, X. Guo et al., The dawn of lead-free perovskite solar cell: highly stable double perovskite $\mathrm{Cs}_{2} \mathrm{AgBiBr}_{6}$ film. Adv. Sci. 5(3), 1700759 (2018). https ://doi.org/10.1002/advs.201700759
98. W. Gao, C. Ran, J. Xi, B. Jiao, W. Zhang, M. Wu, X. Hou, $\mathrm{Z}$. Wu, Quality $\mathrm{Cs}_{2} \mathrm{AgBiBr}_{6}$ double perovskite film for leadfree inverted planar heterojunction solar cells with $2.2 \%$ efficiency. ChemPhysChem 19(14), 1696-1700 (2018). https:// doi.org/10.1002/cphc. 201800346

99. M. Pantaler, K.T. Cho, V.I.E. Queloz, I.G. Benito, C. Fettkenhauer et al., Hysteresis-free lead-free double perovskite solar cells by interface engineering. ACS Energy Lett. 3(8), 17811786 (2018). https://doi.org/10.1021/acsenergylett.8b00871

100. M. Wang, P. Zeng, S. Bai, J. Gu, F. Li, Z. Yang, M. Liu, Highquality sequential-vapor-deposited $\mathrm{Cs}_{2} \mathrm{AgBiBr}_{6}$ thin films for lead-free perovskite solar cells. Solar RRL (2018). https://doi. org/10.1002/solr.201800217

101. X. Qiu, B. Cao, S. Yuan, X. Chen, Z. Qiu et al., room unstable $\mathrm{CsSnI}_{3}$ to air-stable $\mathrm{Cs}_{2} \mathrm{SnI}_{6}$ : a lead-free perovskite solar cell light absorber with bandgap of $1.48 \mathrm{eV}$ and high absorption coefficient. Sol. Energy Mater. Sol. Cells 159, 227-234 (2017). https://doi.org/10.1016/j.solmat.2016.09.022

102. X. Qiu, Y. Jiang, H. Zhang, Z. Qiu, S. Yuan, P. Wang, B. Cao, Lead-free mesoscopic $\mathrm{Cs}_{2} \mathrm{SnI}_{6}$ perovskite solar cells using different nanostructured $\mathrm{ZnO}$ nanorods as electron transport layers. Phys. Status Solidi (RRL) 10(8), 587-591 (2016). https://doi.org/10.1002/pssr.201600166

103. B. Lee, A. Krenselewski, S.I. Baik, D.N. Seidman, R.P.H. Chang, Solution processing of air-stable molecular semiconducting iodosalts, $\mathrm{Cs}_{2} \mathrm{SnI}_{6-\mathrm{x}} \mathrm{Br}_{\mathrm{x}}$, for potential solar cell applications. Sustainable Energy Fuels 1(4), 710-724 (2017). https://doi.org/10.1039/C7SE00100B

104. M. Chen, M.G. Ju, A.D. Carl, Y. Zong, R.L. Grimm et al., Cesium titanium (IV) bromide thin films based stable leadfree perovskite solar cells. Joule 2(3), 558-570 (2018). https ://doi.org/10.1016/j.joule.2018.01.009

105. Q.A. Akkerman, M. Gandini, F. Di Stasio, P. Rastogi, F. Palazon et al., Strongly emissive perovskite nanocrystal inks for high-voltage solar cells. Nat. Energy 2(2), 16194 (2016). https://doi.org/10.1038/nenergy.2016.194

106. Z. Liu, B. Sun, X. Liu, J. Han, H. Ye, T. Shi, Z. Tang, G. Liao, Efficient carbon-based $\mathrm{CsPbr}_{3}$ inorganic perovskite solar cells by using $\mathrm{Cu}$-phthalocyanine as hole transport material. Nano-Micro Lett. 10(2), 34 (2018). https://doi.org/10.1007/ s40820-018-0187-3

107. Y. Chen, X. Wu, Y. Chu, J. Zhou, B. Zhou, J. Huang, Hybrid field-effect transistors and photodetectors based on organic semiconductor and $\mathrm{CsPbI}_{3}$ perovskite nanorods bilayer structure. Nano-Micro Lett. 10(4), 57 (2018). https://doi. org/10.1007/s40820-018-0210-8 